\title{
Analysis of a group purchasing organization under demand and price uncertainty
}

\author{
Oktay Karabă $\breve{g}^{1}$ Barış $\operatorname{Tan}^{2}$
}

Published online: 3 November 2017

(C) Springer Science+Business Media, LLC 2017

\begin{abstract}
Based on an industrial case study, we present a stochastic model of a supply chain consisting of a set of buyers and suppliers and a group purchasing organization (GPO). The GPO combines orders from buyers in a two-period model. Demand and price in the second period are random. An advance selling opportunity is available to all suppliers and buyers in the first-period market. Buyers decide how much to buy through the GPO in the first period and how much to procure from the market at a lower or higher price in the second period. Suppliers determine the amount of capacity to sell through the GPO in the first period and to hold in reserve in order to meet demand in the second period. The GPO conducts a uniform-price reverse auction to select suppliers and decides on the price that will be offered to buyers to maximize its profit. By determining the optimal decisions of buyers, suppliers, and the GPO, we answer the following questions: Do suppliers and buyers benefit from working with a GPO? How do the uncertainty in demand, the share of GPO orders in the advance sales market, and the uncertainty in price influence the players' decisions and profits? What are the characteristics of an environment that would encourage suppliers and buyers to work with a GPO? We show that a GPO helps buyers and suppliers to mitigate demand and price risks effectively while collecting a premium by serving as an intermediary between them.
\end{abstract}

Keywords Applied probability - Stochastic models - Supply chain management · Procurement - Uniform price reverse auction

$\bowtie$ Oktay Karabă̆

okarabag13@ku.edu.tr

Barış Tan

btan@ku.edu.tr

1 College of Engineering, Koç University, Rumeli Feneri Yolu, Istanbul 34450, Turkey

2 College of Administrative Sciences and Economics, Koç University, Rumeli Feneri Yolu, Istanbul 34450, Turkey 


\section{Introduction}

Increasing intensity of competition has led companies to search for new business models that improve their competitiveness and profitability. In situations where companies are not able to achieve these goals on their own, they seek ways to partner with other entities in the market in order to benefit from possible cost reductions, demand pooling effects, higher capacity utilization, and improved flexibility to respond to uncertainty in the business environment (Tan and Akçay 2014). The emergence of group purchasing organizations (GPOs) offers a practical framework to benefit from cooperation in purchasing. Briefly, the term GPO refers to an organization established to capitalize on the purchasing power of a group of businesses. The mechanism is also referred to as joint procurement, purchasing consortium, and cooperative purchasing (Nollet and Beaulieu 2003).

Industry-specific GPOs are observed in many industries such as health care, manufacturing, food service, and pharmaceuticals (Nagarajan et al. 2010; Hu et al. 2012; Jin and Yu 2015). Non-industry-specific GPOs operate across different sectors for procuring common products and fulfill aggregate non-strategic demand for indirect supplies and services. The purchasing volume obtained by a GPO through its members and the possibility of mitigating demand and price risks during the selling season are the key factors that enable vendors to offer discounts. GPOs also offer many services in addition to collective procurement, such as supplier discovery, spend management, sourcing and contracting, data management, and price benchmarking.

This study is based on a project implemented in a company that mainly manages collective procurement of indirect materials and services for its customers. Tan (2014) describes the project in detail as a case study. The company benefits from the economies of scale generated by the collective purchasing power of its customers, from its abilities to support customers' procurement divisions with the expertise of working in different business segments, and from managing supplier relations to ensure the quality of services and products. Accordingly, the business model used in this company is very similar to a group purchasing organization.

Suppliers used in a specific procurement project are selected according to the result of an auction. For example, the logistics services managed and executed by this company cover 810 destinations originating from 81 cities, exports to 65 countries, and imports from 17 countries. This company purchases thousands of containers in a single procurement project. Similarly, for the procurement of marketing materials such as promotional products and on-line portal services, more than 3000 different products and services are offered by organizing approximately 5000 auctions in a year.

Several questions need to be answered to facilitate the successful operation of a GPO: Do all parties in such a supply chain, namely, buyers, suppliers and GPO, always benefit from cooperation on purchasing? Otherwise, how and under what conditions does cooperation lead to non-beneficial outcomes for at least one of the parties? How do factors such as demand variation, wholesale price, supplier capacity, number of suppliers in the GPO, and number of buyers in the GPO 
influence the decision to participate? To address these research questions, we develop a detailed two-period stochastic model with demand and price uncertainty. As opposed to using a stylistic model that may not consider the details of operations in this industrial setting, we fully characterize the optimal decisions of all parties in the detailed model described in this study and determine their expected profits, both with and without a purchasing organization. This analytic model allows us to analyze the effects of system parameters on these decisions and determine the conditions for successful GPO operations.

The main contributions of this study is developing a detailed analytic model of a supply chain with several suppliers and buyers as well as a GPO, and determining the conditions that lead to a beneficial cooperation for all parties in the market, based on an industrial project. To the best of our knowledge, this is the first analytic model in the literature that captures the dynamics of GPO operations and their effects on suppliers and buyers under price and demand uncertainty.

The remainder of this paper is organized as follows. Section 2 provides a review of the literature on supply chain models with group purchasing organizations and contextualizes our contribution. We introduce our analytic model in Sect. 3 and present the analysis in Sect. 4. We summarize the results of the numerical analysis in Sect. 5. Finally, the conclusions and future research directions are provided in Sect. 6.

\section{Literature review}

Numerous studies have examined cooperation among firms on production, distribution, and sales in supply chains (e.g. Gerchak and Diwakar 1991; Benjaafar et al. 2005; Tan and Akçay 2014; Yu et al. 2015). In this section, we focus only on papers dealing with cooperation on procurement. Table 1 compares our work with the existing literature discussed in this section.

The notion of purchasing group organizations and the motives behind using GPOs are empirically discussed in Nollet and Beaulieu (2003), Tella and Virolainen (2005), and Erhun (2010). Only a limited number of studies have analyzed group purchasing organizations analytically. The papers that adopt the buyer's and/or GPO's perspective to analyze the group purchasing mechanisms are listed as follows. Saha et al. (2011) explore the decisions of large-demand buyers who join a GPO but later decide to directly procure from the supplier by renegotiation in an uncertain product price setting. They show that under high price uncertainty, a GPO acts as a demand aggregator for small buyers and as an information provider for large buyers. Chen and Roma (2011) show that group buying is always preferable for homogeneous buyers in a supply chain consisting of a single manufacturer and two buyers who compete for end customers. However, for heterogeneous buyers, group purchasing is beneficial for the smaller buyer whereas it can be detrimental for a larger one. Li (2012) examines the implications of buyer heterogeneity in the context of group buying. The author finds that buyers can benefit from group buying when the sellers' bargaining power relative to that of the buyer group is low and/or buyers' preferences toward sellers are sufficiently differentiated. Zhou and Xie 


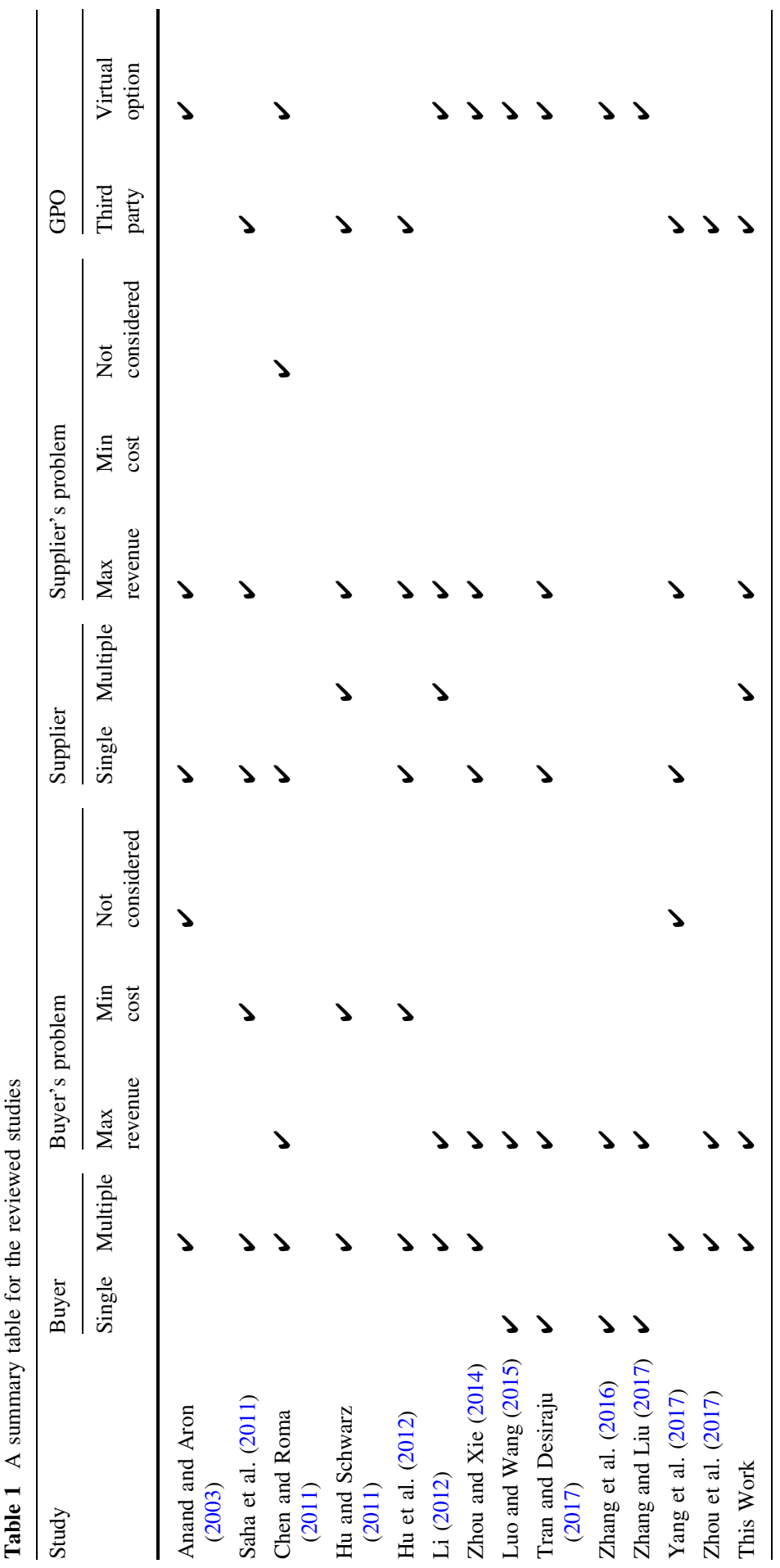




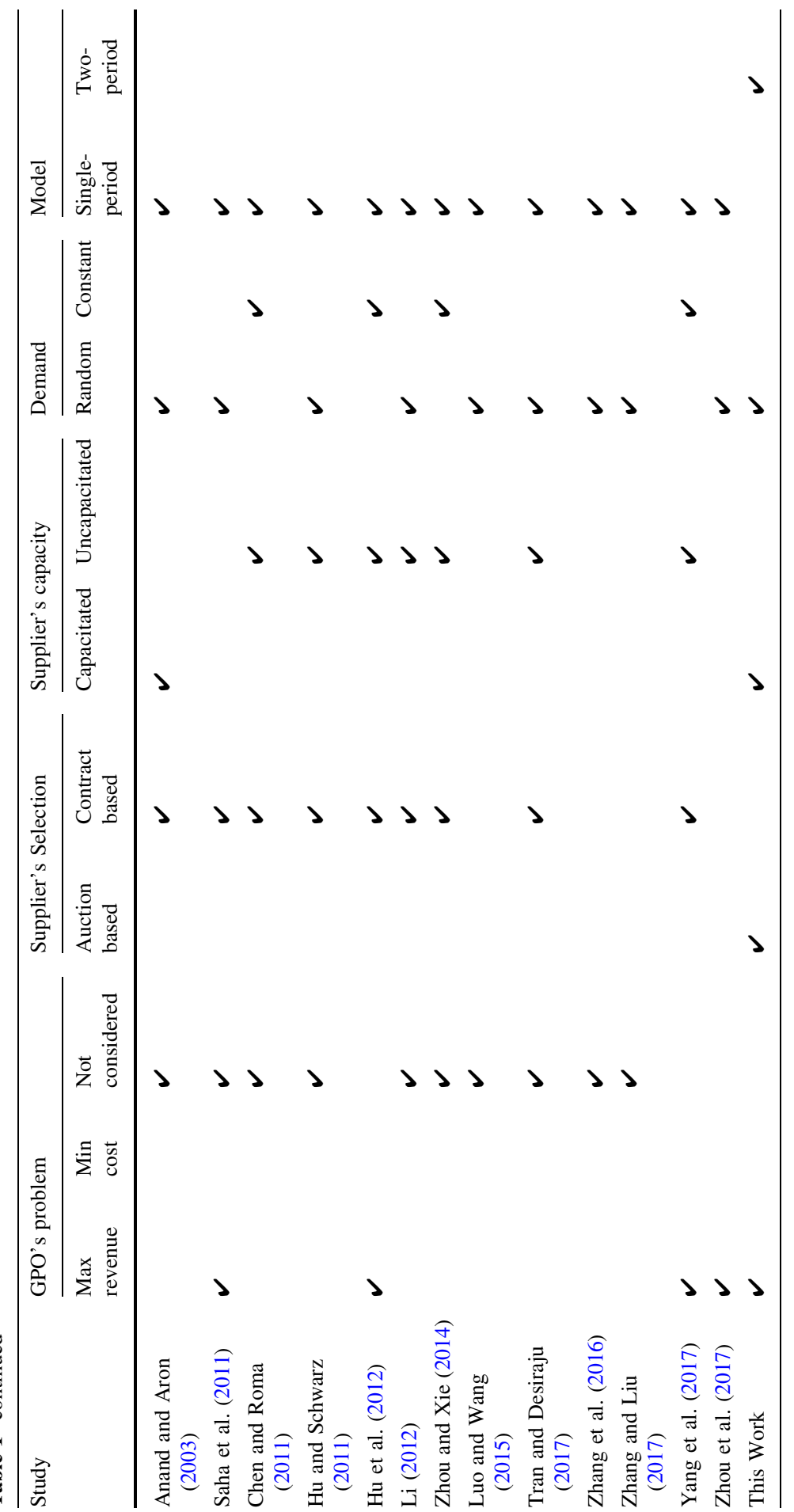


(2014) extend the work of Chen and Roma (2011) by considering the supplier as an active member who determines the discount schedule based on whether retailers choose individual or group buying. They find that group buying may hurt the efficiency of the supply chain, and a mixed discount schedule can be used to prevent these negative effects. In the work of Zhou et al. (2017), the potential role of group purchasing organizations in facilitating information sharing and coordinating horizontal competition is discussed from the buyer's perspective. The authors reveal that a GPO has the opportunity to gain significant advantages by addressing the system inefficiencies due to double marginalization and information asymmetry.

The number of papers that focus on the suppliers perspective in the group buying models is limited. Anand and Aron (2003) analyze the market and product characteristics that incentivize a supplier to use the group buying mechanism and compare the posted-pricing mechanism with the price-quantity schedule offered to the group buying customers in different scenarios involving demand uncertainty and economies of scale. Hu and Schwarz (2011) analytically address the effects of contract administration fees that GPOs charge to suppliers and whether GPOs can reduce procurement prices or total purchasing costs for their members. The authors show that eliminating contract administration fees and having buyers pay for GPOs contracting services instead of suppliers would have no effect on the profit or cost function of any party in the market. Hu et al. (2012) examine the impact of a group purchasing organization on a health-care product supply chain by using a gametheoretic model that consists of a profit-maximizing supplier with a quantitydiscount schedule, a profit-maximizing GPO, and fixed-demand single-product. They show that contract administration fees have a direct impact on the distribution of profits between suppliers and group purchasing organizations. Yang et al. (2017) study the group buying process from the suppliers perspective and emphasize that the number of GPO members strongly influences the suppliers decision either to contract or not with the GPO.

In addition, several studies consider group buying as a virtual sales channel for suppliers, and compare it with the option of selling only to individuals (e.g. Luo and Wang 2015; Tran and Desiraju 2017; Zhang and Liu 2017; Zhang et al. 2016).

Table 1 shows that most of the extant literature considers the GPO as a virtual sales channel and does not explore the effect of group buying mechanism on the revenues of all parties in the supply chain. In addition, none of these studies explore the conditions that lead to a beneficial cooperation for all parties in the market when the suppliers have limited capacity. Our model mainly differs in the detailed operational modeling of a whole supply chain consisting of suppliers with limited capacity, buyers with random demand and price, and a GPO that works with a subset of profit-maximizing suppliers and buyers. The GPO is considered a riskneutral expected-profit maximizer, whose procurement process is modeled as a uniform-price reverse auction mechanism. Price competition between buyers is not considered since they act as a price taker in the market where there are a large number of competitors. However, we allow buyers/suppliers who work with the GPO to negotiate directly with others in the market in the first and second periods before they decide to purchase/sell their commodities through the GPO. To the best of our knowledge, this is the first paper in the literature on GPOs to use detailed 
stochastic modeling of capacity setting, an auction mechanism, and advance order commitments in a two period setting in which demand and price are random.

\section{Model}

The supply chain we examine consists of $h$ symmetrical suppliers, $n$ identical buyers with stochastic demand for a single homogeneous product, and a GPO that operates as an intermediary. Each party in the market is rational, risk-neutral, and seeks to maximize its expected profit. The system is analyzed in two periods. The first period is referred to as the advance selling period, and the second period as the selling season. Advance selling is possible for all parties in the supply chain, and the market price for the advance sales is $w_{f p}$. As an alternative procurement channel, the GPO announces a price for the first period, $w_{r}$, to the potential buyers for the organization. The list of notations used in our model is given Table 2.

\subsection{Time sequence}

The time sequence of the model is depicted in Fig. 1. In the first period, each potential buyer $i, i \in\{1,2, \ldots, n\}$ decides on whether or not to use a GPO. When the option of working with a GPO results in a higher profit than the market option, the buyer procures all its advance orders at a unit price of $w_{r}$ and submits the advance order quantity $q_{G}$ to the GPO. Since buyers are identical, the GPO consolidates $Q_{G}=n q_{G}$ units under this setting. When the buyers use the GPO option in the first period, the structure of advance sales market will be as shown in Fig. 2b. Buyer $i$ prefers to procure $q_{N G}$ units from the advance selling market at a unit price of $w_{f p}$ when the market option is more profitable. If the buyers prefer the market option, that is, when $q_{G}=0$ for each buyer, the GPO cannot function. In the case where there is no functional GPO in the market, the advance sales market structure will be as shown in Fig. 2a.

If $q_{G}>0$, the GPO will organize a uniform-price reverse auction among the potential suppliers in order to procure $Q_{G}$ units. Each potential supplier $j$, where $j \in\{1,2, \ldots, h\}$, is invited to participate in the auction. When the option of working with the GPO is more profitable compared to the market option, supplier $j$ informs the GPO that it will participate in the auction with an allocated capacity of $\Delta_{G}$. Otherwise, supplier $j$ will use the market option for both periods.

The GPO is able to operate only when the total capacity allocated by the suppliers who participate in the auction is sufficient to provide $Q_{G}$ units. When a sufficient number of suppliers do not participate in the auction, no clearing price can be determined. If the GPO cannot function, because buyers prefer the market option or are unable to induce suppliers to allocate the required capacity, the suppliers and the buyers use the market option for the first period.

When the conditions for conducting an auction are met, the participating suppliers submit their price bids to the GPO. The GPO sorts all the submitted bids in an ascending order and announces the winning bidders at the end of the first period. 
Table 2 A list of notations

$h$ : The number of the suppliers who are members of the GPO

$j$ : The index for the suppliers who are members of the GPO

$w_{f p}$ : The market price for the advance sales

$W_{s}$ : The price the GPO pays to the suppliers at the end of auction

$e_{g}$ : The extra transaction cost that the GPO pays for each procured item in the auction

$e_{r}$ : The extra transaction cost that the buyer pays when the market option is used in the first period

$W_{s p}$ : The wholesale price in the second period

$p$ : The price charged by the buyers for the sales in the second period

$q_{G}$ : The advance order quantity when a buyer chooses to work with the GPO option

$q_{N G}$ : The advance order quantity when a buyer chooses to work with the market option

$\tau$ : The portion of the first period market captured by the buyers who are members of the GPO, $\tau=n q_{N G} / Q_{T}^{N G}$

$\gamma$ : The minimum premium guaranteed to the buyers by the GPO

$C_{j}$ : The production cost of supplier $j$ in which it is uniformly distributed over the interval $[\underline{c}, \bar{c}]$

$M$ : The total amount capacity a supplier has before the selling season starts

$\Delta_{N G}$ : The capacity allocated by a participating supplier or non-participating supplier for the advance order market when there is no GPO

$\beta$ : The market share of a buyer on the total demand

$D_{T}$ : Total demand in the market including the first and second periods

$F_{D_{T}}(x)$ : The cumulative distribution function of the total demand, $D_{T}$

$f_{D_{T}}(x)$ : The probability density function of the total demand, $D_{T}$

$D_{s}^{N G}$ : The second-period demand for a supplier when there is no functional GPO in the market, $D_{s}^{N G}=\max \left\{0, \psi\left(D_{T}-Q_{T}^{N G}\right)\right\}$

$F_{D_{s}^{N G}}(z)$ : The conditional cumulative distribution function of $D_{s}^{N G}$

$\theta$ : The lower bound for the probability of obtaining a functional GPO in the market $n$ : The number of the buyers who are members of the GPO

$i$ : The index for the buyers who are members of the GPO

$w_{r}$ : The purchasing price offered by the GPO to the buyers in the first period

$w_{s}$ : The expectation of $W_{s}, E\left[W_{s}\right]=w_{s}$

$\hat{w}_{s}$ : The estimation of the expected auction price in which it is used by the supplier

$e_{s}$ : The extra transaction cost that the supplier pays when the market option is used in the first period

$w_{s p}$ : The expectation of $W_{s p}, E\left[W_{s p}\right]=w_{s p}$

$s$ : The salvage price

$Q_{G}$ : Total advance order quantity consolidated by the GPO

$Q_{T}^{N G}$ : Total amount of advance orders procured in the whole supply chain when there is no functional GPO

$Q_{T}^{G}$ : Total amount of advance orders procured in the whole supply chain when there is a functional GPO

$k$ : The order of the last winning supplier in the auction, $k=\left\lceil Q_{G} / \Delta_{G}\right\rceil$

$H_{a}$ : The number of suppliers that participate in the auction

$\Delta_{G}$ : The capacity that is allocated by a participating supplier for the GPO in the first period

$\Delta_{N G}^{\prime}$ : The capacity allocated by a non-participating supplier for the the advance order market when there is a functional GPO

$\psi$ : The market share of a supplier in the first and second periods

$\beta D_{T}$ : The demand for a buyer

$F_{\mathrm{B}}(y)$ : The cumulative distribution function of the buyer's demand, $\beta D_{T}$

$f_{\mathrm{B}}(y)$ : The probability density function of the buyer's demand, $\beta D_{T}$

$D_{s}^{G}$ : The second-period demand for a supplier when there is a functional GPO in the market, $D_{s}^{G}=\max \left\{0, \psi\left(D_{T}-Q_{T}^{G}\right)\right\}$

$F_{D_{s}^{G}}(u)$ : The conditional cumulative distribution function of $D_{s}^{G}$ 
Since a uniform-price reverse auction is used to determine the price, each winning supplier receives a unit price equal to the lowest losing bid. The advance order quantities are delivered to the buyers immediately after the auction.

Since all deals between the potential buyers and suppliers are completed at the GPO auction in the first period, the losing suppliers cannot sell their capacities in the first period. The losing suppliers, as well as winning suppliers with remaining capacity, can sell their products in the second market, along with the suppliers who did not participate in the auction.

In the second period, the wholesale price at which buyers can absorb the additional supply and the demand are observed. Each buyer' demand is fully met with the additional supply from the suppliers in the market at the second period wholesale price. The buyers charge a retail price for each unit demanded. At the end of the second period, each supplier receives a salvage value for each unit left unsold. Finally, all the transactions are completed and the market clears.

\subsection{Price model}

Since a competitive advance sales market consists of a large number of suppliers and buyers, each individual party in the market acts as a price taker. The market price for advance sales, $w_{f p}$, is considered exogenous and is perfectly known at the time suppliers and buyers decide to participate in the GPO before the selling season starts.

The price that the GPO charges to the buyers, $w_{r}$, is perfectly known to all buyers before they decide whether or not to participate in the GPO. The GPO determines $w_{r}$ so as to maximize its expected profit. The price the GPO pays to the suppliers, $W_{s}$, is determined by an auction mechanism. Therefore, it is a random variable with the expectation $E\left[W_{s}\right]=w_{s}$.

The wholesale price in the second period, $W_{s p}$, is also a random variable with the expectation $E\left[W_{s p}\right]=w_{s p}$. All parties in the market perfectly know $w_{s p}$ before the selling season starts. Since $w_{f p}$ and $w_{r}$ are constant prices known before the selling

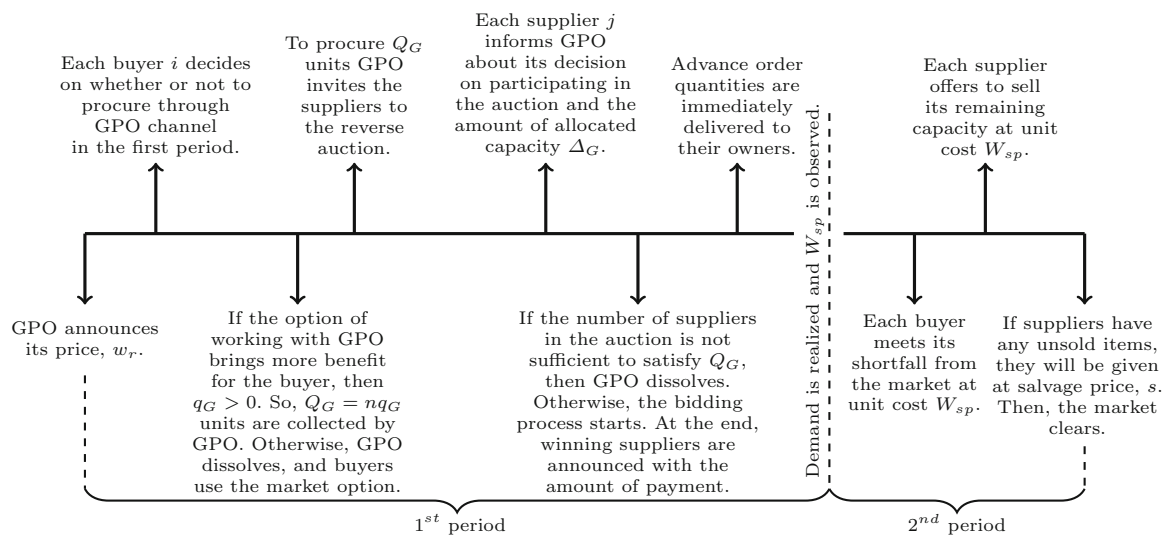

Fig. 1 Time sequence for the model 


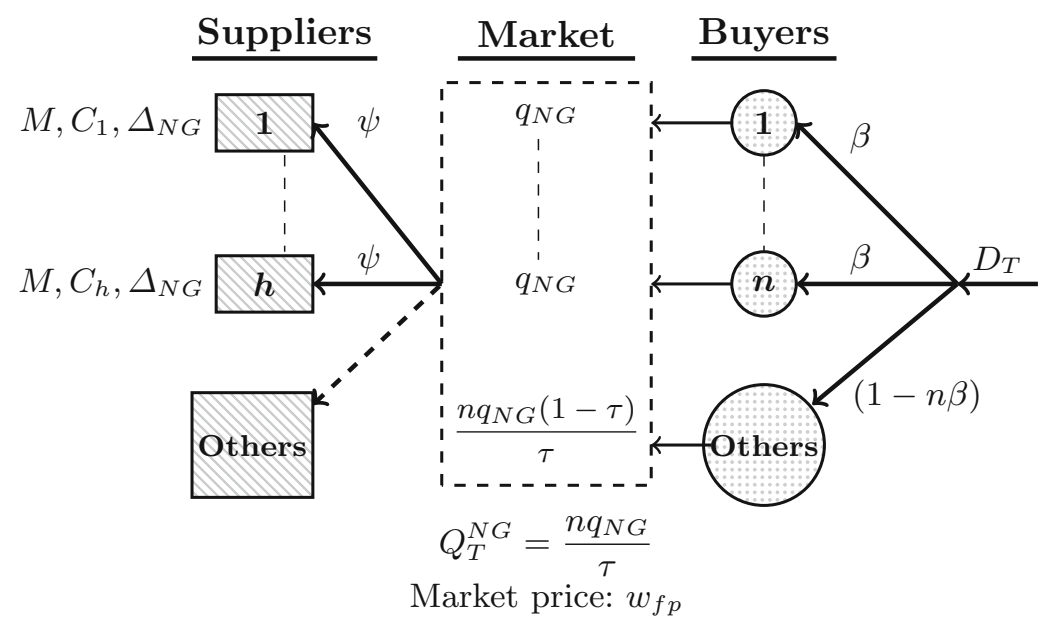

(a)

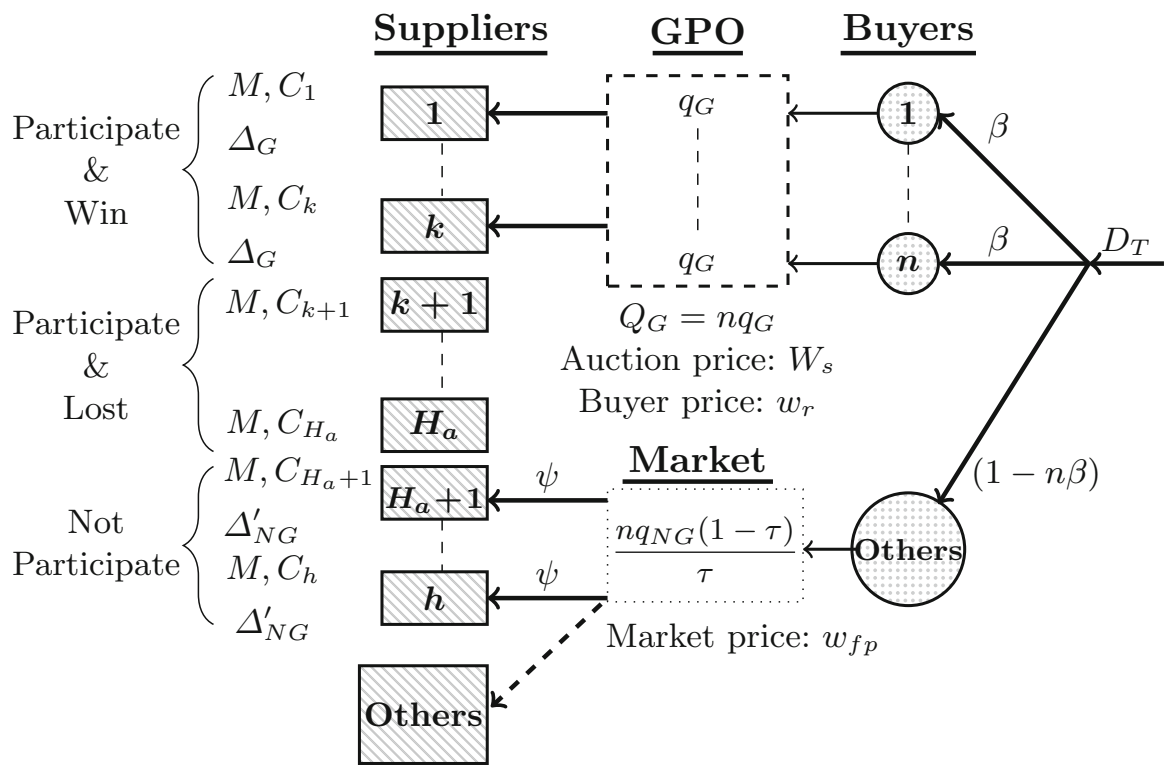

(b)

Fig. 2 Illustrations of the models for the first period $\mathbf{a}$ when there is no GPO, $\mathbf{b}$ when there is a functional GPO in the market

season starts, the wholesale price in the second period is considered as an independent variable from them. In addition, the wholesale price in the second period does not depend the total demand in the market. This consideration can be justified when the market is so competitive that the parties in the market essentially price takers (Zhao et al. 2016). 
The price charged by the buyers for customer sales in the second period, $p$, is constant and given exogenously. We assume that $p>w_{s p}>\max \left\{w_{r}, w_{f p}\right\}$ because operating as a buyer in the market is clearly not profitable when $\max \left\{w_{s p}, w_{r}, w_{f p}\right\} \geq p$ and $w_{s p}>p>\max \left\{w_{r}, w_{f p}\right\}$. In addition, procuring in the first period either through the GPO or through the market does not create added value for the buyer when $\max \left\{p, w_{r}, w_{f p}\right\} \geq w_{s p}$. A case in which advance procurement is possible only through the GPO in this price setting can also be analyzed with $w_{f p}$ set sufficiently high, that is, $w_{f p}>w_{s p}$. The salvage value is denoted by $s$.

\subsection{Demand model}

Total demand in the market, $D_{T}$, includes the demand in the first and second periods. $D_{T}$ is a random variable with the probability density function $f_{D_{T}}(x)$ and the cumulative density function $F_{D_{T}}(x) . F_{D_{T}}(x)$ is a continuous and twice-differentiable function where $F_{D_{T}}(x)=0$ for all $x \leq 0$ and $f_{D_{T}}(x)>0$ for all $x>0$.

Buyer $i, i \in\{1,2, \ldots, n\}$, can get only a portion of the demand, depending on its market share $\beta, 0<\beta<1 / n$. The demand for buyer $i$ is $\beta D_{T}$, which has a cumulative distribution function $F_{\mathrm{B}}(y)$ and density function $f_{\mathrm{B}}(y)$. The other buyers in the market who do not participate in the GPO manage their procurement activities on their own by using the market option for both periods. Their potential demand is the remaining portion of the total demand, that is, $(1-n \beta) D_{T}$.

For both periods, all buyers in the market prioritize the suppliers who are invited to participate in the auction as preferred business partners. Accordingly, the other suppliers are used as a spot market when all potential suppliers for the GPO are unable to satisfy the demand in one of the periods.

When there is no functional GPO in the market, as shown in Fig. 2a, the buyers procure $n q_{N G}$ units of advance orders in total at a unit price of $w_{f p} . n q_{N G}$ captures $\tau$ percent of the whole advance sales market and this information is known to all market participants. In this setting, the total amount of advance orders procured in the whole supply chain, $Q_{T}^{N G}$, is described as $Q_{T}^{N G}=\frac{n q_{N G}}{\tau}$. Since $q_{N G}$ is a decreasing function of $w_{f p}$ and $\tau$ is a constant, the total amount of advance orders procured in the whole supply decreases as the market price for advance sales increases.

The market share of a supplier in the first and second periods is denoted by $\psi$ where $0<\psi<\frac{1}{h}$. With no functional GPO in the market, as shown in Fig. 2a, supplier $j$ can get a maximum of $\psi Q_{T}^{N G}$ units in the first period. Since the total demand decreases by $Q_{T}^{N G}$ units at the end of the first period due to advance sales in the market, the potential suppliers share the remaining demand in the second period according to their market shares. The buyers procure additional supply if their demand in the second period is positive. Accordingly, where there is no functional GPO in the market, the second-period demand for supplier $j, D_{s}^{N G}$, follows a conditional distribution given that it is positive. The conditional cumulative 
distribution function is denoted with $F_{D_{s}^{N G}}(z)$, where $D_{s}^{N G}=\max \left\{0, \psi\left(D_{T}-Q_{T}^{N G}\right)\right\}$ given that $\psi\left(D_{T}-Q_{T}^{N G}\right)>0$.

When there is a functional GPO in the market, as depicted in Fig. 2b, the buyers who are members of the GPO procure $Q_{G}=n q_{G}$ units. Since the other buyers in the market still trade at the market price $w_{f p}$, their total advance order quantity remains the same, equal to $\frac{(1-\tau) n q_{N G}}{\tau}$. In this setting, the total amount of advance orders procured in the whole supply chain is $Q_{T}^{G}=Q_{G}+\frac{(1-\tau) n q_{N G}}{\tau}$ and the buyers who are members of the GPO capture $\frac{Q_{G}}{Q_{T}^{G}}$ percent of the whole advance sales market. Suppliers who participate in the auction compete for a portion of $Q_{G}$ units in the first period, and the non-participating suppliers appropriate the remaining advance orders according to their market shares. After the first period, the total demand in the market decreases by $Q_{T}^{G}$ units. As a result, the supplier's demand in the second period follows a conditional distribution, with the cumulative distribution function being $F_{D_{s}^{G}}(u)$, where $D_{s}^{G}=\max \left\{0, \psi\left(D_{T}-Q_{T}^{G}\right)\right\}$ given that $\psi\left(D_{T}-Q_{T}^{G}\right)>0$.

\subsection{Model of the buyer}

We consider buyers who enter the market to procure a homogeneous non-direct material, such as stationery, a service, or container space for transportation. Therefore, competition between buyers is not considered here.

Buyers always meet their demand either using the GPO in the first period and the market in the second period or using only the market in both periods; that is, there are no lost sales on the buyers' side.

Buyers pay an extra unit of transaction cost, $e_{r}$, for each item procured through their own efforts. This cost covers the expenses for supplier selection, transportation, and administrative services.

\subsection{Model of the supplier}

For all suppliers, an opportunity to install capacity occurs well before the selling season. Therefore, we consider a case where supplier $j$, decides the capacity, $M$, before the selling season starts. In our setting, the production capacity can also be thought of as on-hand inventory before the selling season starts. For instance, the truck fleet or container space that a logistics company owns can also be considered as capacity in our setting.

Each of the potential suppliers for the GPO decides to allocate a portion of its capacity either to the GPO, which will pay a unit price $W_{s}$ in the first period, or to the advance sales market, which will provide a unit price $w_{f p}$. The supplier chooses one of these two possible options according to its expected profit. When supplier $j$ evaluates the option of working with the GPO as more profitable, it decides on the allocated capacity for the GPO, $\Delta_{G}$, and the bid to be submitted in the auction. $\Delta_{G}$ 
cannot be partitioned by the GPO, and it cannot exceed the amount of advance orders consolidated in the GPO, that is, $0 \leq \Delta_{G} \leq Q_{G}$.

The production cost per unit, $C_{j}$, of supplier $j$, is assumed to be private information. Without any information, each party in the market believes that $C_{j}$ is distributed uniformly over the interval $[\underline{c}, \bar{c}]$. To avoid trivial cases, we assume $\underline{c}>s$. Suppliers pay an extra unit transaction cost, $e_{s}$, for each item sold by their own efforts. This cost covers the expenses for transportation and administrative services.

The number of suppliers in the purchasing organization is treated as private information by the GPO in order to avoid collusion. Otherwise, the suppliers may collude to manipulate the auction price, and the GPO will never become functional. Lacking information on the number of suppliers, supplier $j$ uses a single-point estimation of the expected $W_{s}$ to derive its profit function (for a similar assumption, see, e.g., Hao 2000).

The single-point estimation of the expected auction price, $\hat{w}_{s}$, is based on historical data and is common for all suppliers. In the numerical experiments for our setting, we only consider cases where the point estimation of the expected auction price, $\hat{w}_{s}$, does not significantly deviate from the realized value, varying at most by $\pm 5 \%$ of the realized value.

\subsection{Model of the group purchasing organization}

The GPO invites $h$ suppliers to work in the auction. However, the number of suppliers it will work with will depend on the capacities that the suppliers allocate to the GPO. Since each supplier submits an allocated capacity of $\Delta_{G}$ as a batch in the auction, the GPO will work with $k=\left\lceil\frac{Q_{G}}{\Delta_{G}}\right\rceil$ suppliers to fulfill the total advance order quantity coming from its customers. This implies that the amount of $k \Delta_{G}$ is going to be procured at the end of auction, and a portion of the purchased items, $\left(k \Delta_{G}-Q_{G}\right)$, remains in the hands of the GPO. The excess amount of the purchased products is assumed to be sold at the salvage price $s$.

If the GPO attempts to compete with suppliers by selling the remaining amount of supply in the second period, the market will collapse for the suppliers, and the GPO will be the monopolist. Accordingly, no suppliers may be willing to work with the GPO. The competition boards in practice make regulations on these issues to preserve the fair market competition and to prevent market manipulations. In this setting, making the GPO sell the extra amount of supply at the salvage value forces the GPO to match supply and demand as closely as possible.

The GPO also pays an extra unit transaction cost, $e_{g}$, for each procured item in the auction. This cost covers the expenses for transportation, supplier selection, and administrative services. The effect of economies of scale on the transaction cost is imposed considering that $\max \left\{e_{s}, e_{r}\right\} \geq e_{g}$.

Since the number of suppliers in the GPO is not public information in the market, the suppliers and buyers are not able to estimate the probability of existence of a functional purchasing organization. The GPO therefore specifies a lower bound for 
the probability of obtaining a functional GPO in the market, represented by $\theta$. $\theta$ can be considered as a service level that is offered by the GPO to its partners. In practice, it is estimated from the historical data set and justified based on the experts' opinions. Specifically, the parties in the market use $\theta$ to decide whether to participate in the auction. This information is shared truthfully with the other parties in the market (for a similar analysis, see, e.g., Moinzadeh 2002; Cachon and Marshall 2000; Aviv and Federgruen 1998).

\section{Analysis of the model}

In this section, we analyze the described model and present the analysis results. For clarity, we normalize all financial parameters to the salvage value $s$ by setting $s=0$ without loss of generality.

Before analyzing the model, we introduce a particular setting as an example to clarify the operation of a GPO and the modeling assumptions. In the model, we consider a particular setting where the buyers are identical in terms of the unit production cost, retailing price, and demand for analytical tractability of the model. This particular setting can be used to model firms that work with powerful buyers. For example, in textile-apparel industry, a large buyer works with many small-tomedium size firms and sets a price for its products considering the market conditions. A small firm cannot influence the market price dynamics and only compete to get an order. Additionally, although different styles of apparel products may vary greatly in their characters such as color and appearance, there is typically no significant difference in the production costs (Zhou et al. 2015). In such a setting, in order to decrease the production or procurement costs, the firms typically either join or form a group purchasing organization and collectively manage the procurement of indirect materials and services.

With the market structure mentioned above, let us consider collaborative procurement of containers used by a group of firms to ship products to a particular location. The market price for container shipments directly depends on the fuel cost used to transfer the items from one destination to another. As a result, the market price for the current market (the advance selling period) is typically known by all parties in the market. However, since the fuel price fluctuates according to the commodity market and since the global demand for containers changes with time, the market price for container shipments for the next period (the selling season) is uncertain. Therefore, the suppliers and buyers generally use the advance sales option to mitigate the price risks effectively. Under this setting, the only difference among the suppliers is the fixed cost related to installed capacity, i.e., truck fleet and containers. Due to this fact, in our setting, the suppliers differ from each other in terms of the production cost or service cost.

Before an auction takes place, the GPO performs a comprehensive cost analysis to determine the reasonable price and success probability for the project. Given the price offered by the GPO, the market price in the advance sales period, and the market price in the selling season, each firm first decides how many containers it will buy from the GPO. If the buyers are interested, the GPO consolidates these 
orders and invites suppliers to an auction for, say, a total of 2000 containers for its members. A supplier who has 100 containers available may decide to allocate 80 of them to the GPO, which organizes an auction for the procurement. We assume that if this supplier firm is deemed to be one of the winners of the auction, it supplies 80 containers, but does not accept requests for the supply of, say, 73 containers. The supplier solves an optimization problem to determine the number of containers that will be offered to the GPO in the advance sales period and the number of containers that will be kept for the market in the sales season. In this optimization, the suppliers know that if the total demand for containers is 10,000 on average, the GPO, which procures 2000 containers in the advance selling period, decreases the available demand for them in the selling season. From this information, the GPO can determine how the buyers and suppliers will decide to optimize their expected profits. The GPO consolidates the information to determine the price that will be offered to the buyers to maximize its expected profit.

\subsection{Analysis of buyers}

For a buyer who considers working directly with the suppliers in the first period, without joining the GPO, the expected profit, $E\left[\Pi_{r}^{N G}\left(q_{N G}\right)\right]$, is

$$
E\left[\Pi_{r}^{N G}\left(q_{N G}\right)\right]=p E\left[\beta D_{T}\right]-\left(w_{f p}+e_{r}\right) q_{N G}-\left(w_{s p}+e_{r}\right) E\left[\left(\beta D_{T}-q_{N G}\right)^{+}\right] .
$$

The first term is the total revenue, the second term is the cost of advance purchasing, and the last term is the cost of purchasing in the second period.

For a buyer who considers the option of working with the GPO in the first period, the estimated profit function is given as

$$
\begin{aligned}
E\left[\hat{\Pi}_{r}^{G}\left(q_{G}\right)\right]= & \theta\left(p E\left[\beta D_{T}\right]-w_{r} q_{G}-\left(w_{s p}+e_{r}\right) E\left[\left(\beta D_{T}-q_{G}\right)^{+}\right]\right) \\
& +(1-\theta) E\left[\Pi_{r}^{N G}\left(q_{N G}\right)\right] .
\end{aligned}
$$

The first term represents the buyer's profit when there is a functional GPO in the market, and the second term denotes the buyer's profit when the GPO cannot operate due to an insufficient number of suppliers in the auction.

Note that the buyer analysis is based on the lower bound of the probability that a functional GPO operates in the market, $\theta$. Using the probability that a functional GPO operates in the market instead of the lower bound, we can obtain the expected profit for the buyer, $E\left[\Pi_{r}^{G}\left(q_{G}\right)\right]$. Since $\theta$ is the lower bound, the buyer's expected profit is always more than or equal to the expected profit obtained by using the estimated probability.

The optimal advance order quantities for the market and GPO options are derived by maximization of the expected profit functions in Eqs. (1) and (2), respectively. The optimal order quantities for both the options are stated in the following proposition. The proofs are provided in "Appendix A".

Proposition 1 For a given $w_{r}$ quoted by the GPO, the buyer will work with the GPO in the first period when $E\left[\hat{\Pi}_{r}^{G}\left(q_{G}^{*}\right)\right]-E\left[\Pi_{r}^{N G}\left(q_{N G}^{*}\right)\right] \geq 0$. In this case, the optimal advance order quantity is defined as 


$$
q_{G}^{*}=\left\{\begin{array}{cl}
F_{\mathrm{B}}^{-1}\left(1-\frac{w_{r}}{w_{s p}+e_{r}}\right) & \text { if } w_{s p}+e_{r} \geq w_{r} \geq 0 \\
0 & \text { otherwise }
\end{array} .\right.
$$

In addition, the total advance order quantity consolidated in the GPO is $Q_{G}^{*}=n q_{G}^{*}$.

On the other hand, when $E\left[\hat{\Pi}_{r}^{G}\left(q_{G}^{*}\right)\right]-E\left[\Pi_{r}^{N G}\left(q_{N G}^{*}\right)\right]<0$, the buyer will use the market option in the first period and

$$
q_{N G}^{*}=\left\{\begin{array}{cl}
F_{\mathrm{B}}^{-1}\left(1-\frac{w_{f p}+e_{r}}{w_{s p}+e_{r}}\right) & \text { if } w_{s p}+e_{r} \geq w_{f p}+e_{r} \geq 0 \\
0 & \text { otherwise }
\end{array} .\right.
$$

Comparing $E\left[\hat{\Pi}_{r}^{G}\left(q_{G}^{*}\right)\right]$ with $E\left[\Pi_{r}^{N G}\left(q_{N G}^{*}\right)\right]$ gives the condition that induces the buyer to work with the GPO, as stated in the following proposition.

Proposition 2 For the given parameters $w_{s p}+e_{r} \geq \max \left\{w_{r}, w_{f p}+e_{r}\right\}$, the buyer will work with GPO in first period when $w_{r} \leq w_{f p}+e_{r}$.

\subsection{Analysis of suppliers}

Each supplier decides whether to participate in the auction with no information on the number of suppliers in the GPO. Therefore, a supplier's profit function is derived from the estimated auction price and the lower bound of the probability that a functional GPO operates in the market. Supplier $j$ does not expect to be one of the winners in the auction if its production cost, $C_{j}=c$, is greater than or equal to the estimated auction price, that is, $c \geq \hat{w}_{s}$. If the supplier prefers to participate in the auction rather than use the market option where $c \geq \hat{w}_{s}$, the supplier will have no chance of selling its capacity to the GPO, and will lose the opportunity to join the advance selling market. Therefore, where a supplier loses the auction with a GPO operating in the market, the supplier's expected profit function is defined as in the first component of the following equation; the second term represents a case with no functional GPO in the market:

$$
\begin{aligned}
E\left[\hat{\Pi}_{s_{j}}^{G}\left(\Delta_{N G}\right) \mid c \geq \hat{w}_{s}\right]= & \theta\left(\left(w_{s p}-e_{s}\right) E\left[\min \left\{M, D_{s}^{G}\right\}\right]-c M\right) \\
& +(1-\theta)\left(\left(w_{f p}-e_{s}\right) \Delta_{N G}\right. \\
& \left.+\left(w_{s p}-e_{s}\right) E\left[\min \left(M-\Delta_{N G}, D_{s}^{N G}\right)\right]-c M\right) .
\end{aligned}
$$

On the other hand, a supplier whose production cost is less than $\hat{w}_{s}$ expects to be one of the winners in the auction. However, the probability of winning in the auction cannot be determined by the supplier. The supplier derives its expected profit function with the expectation that it would definitely win at the end of the auction. Thus, the expected profit function of the supplier is defined as 


$$
\begin{aligned}
E\left[\hat{\Pi}_{s_{j}}^{G}\left(\Delta_{G}, \Delta_{N G}\right) \mid c<\hat{w}_{s}\right]= & \theta\left(\hat{w}_{s} \Delta_{G}+\left(w_{s p}-e_{s}\right) E\left[\min \left\{M-\Delta_{G}, D_{s}^{G}\right\}\right]-c M\right) \\
& +(1-\theta)\left(\left(w_{f p}-e_{s}\right) \Delta_{N G}\right. \\
& \left.+\left(w_{s p}-e_{s}\right) E\left[\min \left(M-\Delta_{N G}, D_{s}^{N G}\right)\right]-c M\right)
\end{aligned}
$$

The first term is the expected profit of the supplier given that a GPO is operational and the supplier is one of the winners at the end of the auction. The second term represents a case in which no GPO can operate in the market.

Once a supplier decides to trade with the market in the first period, its expected profit does not change based on whether its production cost is greater than or equal to $\hat{w}_{s}$. Accordingly, the expected profit of the supplier selling to the market in the first period is the same for suppliers with $c<\hat{w}_{s}$ and $c \geq \hat{w}_{s}$, and is given as

$$
\begin{aligned}
E\left[\Pi_{s_{j}}^{N G}\left(\Delta_{N G}^{\prime}, \Delta_{N G}\right) \mid c\right]= & \theta\left(\left(w_{f p}-e_{s}\right) \Delta_{N G}^{\prime}\right. \\
& \left.+\left(w_{s p}-e_{s}\right) E\left[\min \left(M-\Delta_{N G}^{\prime}, D_{s}^{G}\right)\right]\right)-c M \\
& +(1-\theta)\left(\left(w_{f p}-e_{s}\right) \Delta_{N G}\right. \\
& \left.+\left(w_{s p}-e_{s}\right) E\left[\min \left(M-\Delta_{N G}, D_{s}^{N G}\right)\right]\right) .
\end{aligned}
$$

The first component expresses the profit function for a case where a GPO operates but the supplier does not participate in the auction. The second term represents a case where there is no functional GPO in the market. Essentially, for both of the components, the total revenue for the supplier can be expressed as the sum of revenues obtained from sales to individual buyers in the first and second periods. However, since the second-period demand for supplier $j$ directly depends on whether or not a functional GPO operates in the market, the allocated capacity for the advance order market changes. When no GPO can operate due to an insufficient number of suppliers in the auction, a non-participating supplier allocates $\Delta_{N G}$ units of its capacity for the advance order market. On the other hand, if an operational GPO exists in the market, the allocated capacity for the first period will be $\Delta_{N G}^{\prime}$.

The optimal allocated capacities for all the options are expressed in Proposition 3.

Proposition 3 If the GPO yields more benefits for supplier $j$, with production cost less than the estimated auction price, the supplier will be eager to trade with the GPO. In this case, it allocates

$$
\Delta_{G}^{*}=\left\{\begin{array}{cl}
\min \left\{\max \left\{0, M-F_{D_{s}^{G}}^{-1}\left(1-\frac{\hat{w}_{s}}{w_{s p}-e_{s}}\right)\right\}, Q_{G}^{*}\right\} & \text { if } w_{s p}-e_{s} \geq \hat{w}_{s} \geq 0 . \\
0 & \text { otherwise }
\end{array}\right.
$$

Supplier jnever assigns a portion of its capacity to the GPO if its production cost cis greater than or equal to the estimated auction price, that is, $c \geq \hat{w}_{s}$. 
When a supplier evaluates the market option as more beneficial, the portion of its capacity that it will allocate to the buyers in the market when the GPO is operational is given as

$$
\Delta_{N G}^{\prime *}=\left\{\begin{array}{cl}
\min \left\{\max \left\{0, M-F_{D_{s}^{G}}^{-1}\left(\frac{w_{s p}-w_{f p}}{w_{s p}-e_{s}}\right)\right\}, \psi \frac{n q_{N G}(1-\tau)}{\tau}\right\} & \begin{array}{c}
\text { if } w_{s p}-e_{s} \geq w_{s p}-w_{f p} \geq 0 \\
0
\end{array} \text { otherwise }
\end{array}\right.
$$

The portion allocated to the buyers when no GPO is operational in the market is given as

$$
\Delta_{N G}^{*}=\left\{\begin{array}{cc}
\min \left\{\max \left\{0, M-F_{D_{s}^{N G}}^{-1}\left(\frac{w_{s p}-w_{f p}}{w_{s p}-e_{s}}\right)\right\}, \psi Q_{T}^{N G}\right\} & \text { if } w_{s p}-e_{s} \geq w_{s p}-w_{f p} \geq 0 . \\
0 & \text { otherwise }
\end{array}\right.
$$

The condition that induces a supplier to favorably evaluate the option of working with the GPO, in terms of the expressions of allocated capacities for the different cases above, is stated in the following proposition.

Proposition 4 When a supplier's production cost is less than the estimated auction price, the supplier considers the GPO beneficial to it if and only if the following inequality holds.

$$
\Delta_{N G}^{\prime *}\left(1-\frac{w_{f p}-e_{s}}{w_{s p}-e_{s}}\right)-\Delta_{G}^{*}\left(1-\frac{\hat{w}_{s}}{w_{s p}-e_{s}}\right)+\int_{0}^{M-\Delta_{N G}^{*}} F_{D_{s}^{G}}(u) d u-\int_{0}^{M-\Delta_{G}^{*}} F_{D_{s}^{G}}(u) d u \geq 0
$$

when $\hat{w}_{s} \geq w_{f p}-e_{s}$ and $w_{r} \leq w_{f p}+e_{r}$, the above inequality definitely holds. With $c<\hat{w}_{s}$, therefore, supplier jbelieves that the GPO will be beneficial.

On the other hand, suppliers whose production costs are greater than or equal to the estimated auction price would never believe that the GPO is beneficial for them. Therefore, they would never participate in the auction.

Proposition 4 implies that given $c<\hat{w}_{s}$, supplier $j$ definitely chooses the GPO option in the market when it believes the auction price will be higher than the market price in the first period and the GPO plays a market maker role for the suppliers.

Since a supplier uses the estimated auction price to make its capacity allocation decision, its expected profit will be different than the estimated one. With the chosen optimal capacity allocations, the expected profit function for any supplier $j$ is 


$$
\begin{aligned}
E\left[\Pi_{s_{j}}^{G}\left(\Delta_{G}^{*}, \Delta_{N G}^{*}\right) \mid c\right]= & P\left\{H_{a} \geq k+1\right\} P\left\{c<W_{s}\right\} w_{s} \Delta_{G}^{*} \\
& +P\left\{H_{a} \geq k+1\right\} P\left\{c<W_{s}\right\}\left(w_{s p}-e_{s}\right) E\left[\min \left\{M-\Delta_{G}^{*}, D_{s}^{G}\right\}\right] \\
& +P\left\{H_{a} \geq k+1\right\} P\left\{c \geq W_{s}\right\}\left(\left(w_{s p}-e_{s}\right) E\left[\min \left\{M, D_{s}^{G}\right\}\right]\right) \\
& +P\left\{H_{a}<k+1\right\}\left(w_{f p}-e_{s}\right) \Delta_{N G}^{*}-c M \\
& +P\left\{H_{a}<k+1\right\}\left(w_{s p}-e_{s}\right) E\left[\min \left(M-\Delta_{N G}^{*}, D_{s}^{N G}\right)\right]
\end{aligned}
$$

where $w_{s}$ is the expected auction price, $H_{a}$ is the number of bidders in the auction, and $P\left\{H_{a} \geq k+1\right\}$ is the probability of obtaining an operational GPO in the market. These terms are detailed in the next section.

Since the auction price is the lowest losing bid, the probability of being one of the winners in the auction is equivalent to $P\left\{C_{j}=c<W_{s}\right\}=P\left\{C_{j}=c<C_{(k+1)}\right\}$. Considering the fact that for any selected supplier $j, c$ can be assigned to $k$ empty places before the $(k+1)$ th order and it can be selected from $h$ suppliers, this probability is defined as $P\left\{C_{j}=c<C_{(k+1)}\right\}=\frac{k}{h}$.

\subsection{Analysis of auction}

With incomplete information on the suppliers' production costs, the GPO uses a uniform-price reverse auction to select the suppliers and determine the purchasing price. The uniform-price reverse auction is a multi-unit auction in which a fixed number of identical units of a homogeneous commodity are purchased for the same price (Krishna 2002). In our model, the assumptions on the auction and suppliers guarantee that the discriminatory auction, in which identical units of a single item are sold at different prices, and the uniform-price auction yield the same expected revenue for the GPO. We next investigate the bidding behavior of the suppliers when they participate in such a purchasing organization with a uniform-price reverse auction in a two-period stochastic model. Proposition 5 states that bidding a value other than the supplier's actual production cost does not improve the supplier's payoff in this structure.

Proposition 5 When every bidder demands just a single batch, and can indeed bid for only one batch, a Bayesian-Nash equilibrium results such that all bidders reveal their true condition; that is, the suppliers bid at their actual production costs.

The above proposition shows that the dominant strategy for a supplier is to reveal the truth and bid at its actual cost. The main rationale behind this result is that the supplier cannot set $\Delta_{G}$ strategically to manipulate the auction price due to lack of information on the number of suppliers in the GPO.

If the conditions required for a GPO to operate in the market are met, only suppliers whose production cost is less than $\hat{w}_{s}$ might participate in the auction. Since the unit production cost is a supplier's private information, and the other parties in the market only know the distribution that it follows, the number of suppliers that participate in the auction, $H_{a}$, is a random variable. It is expressed as 


$$
H_{a}=\sum_{j=1}^{h} I_{\left\{C_{j}<\hat{w}_{s}\right\}}
$$

where $I$ is an indicator function that takes 0 or 1 depending on the condition $C_{j}<\hat{w}_{s}$. Therefore, $H_{a}$ has a binomial distribution with the following probability mass function:

$$
P\left\{H_{a}=m\right\}=\left(\begin{array}{c}
h \\
m
\end{array}\right) p_{a}^{m}\left(1-p_{a}\right)^{h-m} \quad \text { where } p_{a}=P\left\{C_{j}<\hat{w}_{s}\right\}=\frac{\hat{w}_{s}-\underline{c}}{\bar{c}-\underline{c}} .
$$

To be able to perform a uniform-price reverse auction, the number of suppliers in the auction must be greater than or equal to $(k+1)$. Otherwise, the clearing price cannot be determined and no purchasing organization would be functional. Therefore, the probability of obtaining a functional GPO in the market is defined as

$$
P\left\{H_{a} \geq k+1\right\}=\sum_{m=k+1}^{h}\left(\begin{array}{l}
h \\
m
\end{array}\right) p_{a}^{m}\left(1-p_{a}\right)^{h-m} \quad \text { where } k=\left\lceil\frac{Q_{G}}{\Delta_{G}}\right\rceil .
$$

When there is a functional GPO in the market, the $(k+1)$ st minimum of $H_{a}$ uniformly distributed numbers is paid to all winners. The expectation regarding this payment is given in the following proposition.

Proposition 6 When the production cost of each supplier who participates in the auction is uniformly distributed between $\underline{c}$ and $\hat{w}_{s}$ and when the number of bidders $H_{a}$ follows a binomial distribution, the expected auction price, $w_{s}$, is defined as in the following expression:

$$
\begin{aligned}
w_{s} & =E\left[W_{s}\right]=E\left[C_{(k+1)} \mid H_{a} \geq k+1\right] \\
& =\underline{c}+\left(\hat{w}_{s}-\underline{c}\right)\left(\frac{k+1}{(h+1) p_{a}}-\frac{\left(\begin{array}{c}
h-1 \\
k
\end{array}\right) h p_{a}^{k}\left(1-p_{a}\right)^{h-k}}{(h+1) P\left\{H_{a} \geq k+1\right\}}\right)
\end{aligned}
$$

\subsection{Analysis of the group purchasing organization}

The risk-neutral GPO sets the value of $w_{r}$ by solving the following optimization problem:

$$
\begin{aligned}
& \max _{w_{r} \in\left[0,(1-\gamma)\left(w_{f p}+e_{r}\right)\right]} E\left[\Pi_{G P O}\right]=P\left\{H_{a} \geq k+1\right\}\left(Q_{G}^{*} w_{r}-k \Delta_{G}^{*}\left(w_{s}+e_{g}\right)\right) \\
& \text { s.to } E\left[\Pi_{r}^{G}\left(q_{G}^{*}\right)\right]-E\left[\Pi_{r}^{N G}\left(q_{N G}^{*}\right)\right] \geq \mathcal{E} \\
& P\left\{H_{a} \geq k+1\right\} \geq \theta
\end{aligned}
$$




$$
E\left[\Pi_{G P O}\right] \geq 0
$$

Equation (17) gives the GPO's expected profit, that is, the difference between the total amount of money received from the buyers and the total amount of money paid to suppliers plus transaction expenses.

The individual rationality constraint for a single buyer is defined as in Eq. (18). The GPO knows that buyers would not join the organization without an incentivethe increased profit that the GPO option provides. To encourage buyer participation, the GPO provides a minimum premium to each buyer, setting its offered price at the maximum of $(1-\gamma)\left(w_{f p}+e_{r}\right)$, where $\gamma \in[0,1]$. Hence, it guarantees that buyers obtain premiums from the GPO. Thus, the incentive rationality constraint for the buyers would always be greater than a positive $\mathcal{E}$ value. Since potential buyers are identical, it is sufficient that a single buyer meet this constraint.

Since the GPO shares the lower bound of the probability that a GPO operates in the market with its partners, Eq. (19) ensures that the probability of a functional GPO operating in the market is greater than or equal to this value. Finally, Eq. (20) ensures that operating in the market is beneficial for the GPO.

Since $k$ is defined as the rounded-up value of a fraction involving $Q_{G}^{*}$ in Eq. (15), the objective function has a discontinuous form, which means it contains one or more breaks on $\left[0,(1-\gamma)\left(w_{f p}+e_{r}\right)\right]$. In addition, $Q_{G}^{*}$ and $\Delta_{G}^{*}$, defined in Eqs. (3) and (8), are the partial functions of $w_{r}$. From these results, the above problem has a non-linear objective function that does not yield a closed-form solution when optimized with respect to $w_{r}$ for the general case. In order to determine the optimal value of $w_{r}$ numerically, we use a uniform line search algorithm over the closed interval $\left[0,(1-\gamma)\left(w_{f p}+e_{r}\right)\right] . w_{r}$, which has the largest value for Eq. (17) and satisfies all the constraints, is picked as the solution of the problem. If there is no solution such that all constraints are satisfied, then it is concluded that the GPO would not be functional for that set of system parameters.

\section{Numerical results}

In this section, we investigate the effects of system parameters by using an analytic model that describes the optimal decisions of suppliers, buyers, and the GPO through numerical experiments. All the analytic results are validated by a simulation of the system. Since the results depend on the optimal decisions of the buyers, suppliers, and the GPO, the analytic results derived in this study allow evaluation of the system much more efficiently compared to a similar performance evaluation study based on simulation.

For all instances, the system parameters are set as follows: The retail price $p$, which is charged from the end customer for each of the demanded units, is assigned as $p=45$. Since it would not affect any decisions that parties in the market take, only a single value for this parameter is considered in the numerical analysis. The minimum premium guaranteed to the buyers by the GPO set to $\gamma=10 \%$ for all instances, as stated in the work of Tan (2014). The lower bound of the probability of 
obtaining a functional GPO should be chosen as high as possible, therefore it is set to $\theta=90 \%$. The extra transaction costs for the buyers, suppliers, and the GPO are selected as $e_{r}=5, e_{s}=3$, and $e_{g}=1$, respectively. In all instances, the total demand distribution, $D_{T}$, is assumed to be uniform. Under the uniform demand assumption, Propositions 1, 3, and 4 can be stated in a closed form. The closed-form expressions for the uniformly distributed demand case are given in "Appendix B". In addition, we only consider cases where the point estimation for the expected auction price $\hat{w}_{s}$ varies at most by $\pm 5 \%$ of its realized value, that is, $\left|w_{s}-\hat{w}_{s}\right| \leq 0.05 w_{s}$, in order to limit the effects of wrong estimations on the results.

We use a wide range of test problems in order to assess the effects of buyers' and suppliers' market shares, the variability of production cost, the variability of total demand, the market price for advance sales, and the share of GPO orders in the advance sales market on the profits of the parties in the supply chain. For this purpose, we consider variations around the base scenario introduced in above. At the beginning of each subsection where we address the effect of considered parameters, we present the details related to how these variations are configured. For the range of parameters analyzed in the numerical experiments, the GPO's optimization problem defined in Sect. 4.4 gives the optimal price offered by the GPO to its customers as $w_{r}^{*}=(1-\gamma)\left(w+e_{r}\right)$. That means that the buyers enjoy higher profits compared to the market option, since $w_{r}^{*}$ is always less than the sum of transaction expenses for the buyer and market price for the first period, when GPO is functional. With these arguments, the premium that the buyer gains from the GPO can be directly determined for a given set of parameters. Therefore, the numerical analysis related to the buyer's profit is not presented in this section. In addition, to see whether a GPO is indeed beneficial for supplier $j$, we define $\nabla \Pi_{s_{j}}=$ $E\left[\Pi_{s_{j}}^{G}\left(\Delta_{G}^{*}, \Delta_{N G}^{*}\right) \mid c\right]-E\left[\Pi_{s_{j}}^{N G}\left(\Delta_{N G}^{* *}, \Delta_{N G}^{*}\right) \mid c\right]$ and use it in the numerical analysis of the supplier's expected profit.

\subsection{Effects of buyer's and supplier's market shares}

For the analysis of the impacts of buyer's and supplier's market shares on the profits of the parties in the supply chain, we define a basic scenario where $w_{s p}=30$, $w_{f p}=20, p=45, n=10, \tau=70 \%, \underline{d}_{T}=50,000, \bar{d}_{T}=80,000, \underline{c}=10, \bar{c}=12$, $e_{r}=5, e_{s}=3, e_{g}=1, M=10,000, \theta=90 \%$, and $\gamma=10 \%$. We create three different variations of the scenario considering the following values for the buyer's market share: $n \beta=0.33(n=10, \beta=0.033), n \beta=0.50(n=10, \beta=0.05)$, and $n \beta=0.67$ ( $n=10, \beta=0.067)$. In each variation, the suppliers' total market share, $h \psi$, is changed from 0.02 to 0.98 with an incremental value of 0.02 . For the given values of buyer's market share and suppliers' total market share, we generate a set of problem instances by ranging the number of suppliers from 30 to 80, i.e., $h \in\{30,31,32, \ldots, 80\}$. With this configuration setting, 2499 problem instances are generated for every variation of the basic scenario.

In each set of problem configured for the given values of buyer's market share and suppliers' total market share, the average, maximum, and minimum of the 
profits that the GPO and supplier obtain are determined. They are depicted for the GPO and supplier in Figs. 3 and 4, respectively.

Having partners with a strong market position in terms of market share in the supply and demand markets affects the expected profit functions of the GPO and the suppliers. Figure 3 shows that an increase in the buyer's market share has a positive impact on the expected profit of the GPO. Because, the GPO sells more advance orders to its customers with an increase in $\beta$, the revenue from advance sales increases. Figure 3 also indicates that the average profit level of the GPO increases as the market share of a supplier increases for a given $n \beta$. The main rationale behind this pattern is that the amount of excess inventory potentially due to batch selling in the auction, $\left(Q_{G}-k \Delta_{G}\right)$, decreases as the supplier's market share increases.

Figure 4 shows that the GPO is highly beneficial for the supplier when the total market share of the suppliers in the GPO is less than $h \psi=0.2$. As the market share of a supplier increases for a given $n \beta$, the marginal benefit of the GPO decreases for the supplier and converges to almost zero after $h \psi=0.9$. Figure 4 also indicates that an upward change in the buyer's market share increases the benefit that a supplier derives from the GPO. However, with an increase in the supplier's market share, the positive impact of the high $\beta$ in the expected profit function of supplier also disappears. These observations imply that the GPO serves as a market maker for the supplier in case of a small market share for a single supplier, $\psi$, and a high market share for a single buyer in the GPO, $\beta$, so that the supplier benefits more from the GPO.

\subsection{Effects of market price for advance sales and share of GPO order in the advance sales market}

In order to analyze the impacts of market price for advance sales and share of GPO order in the advance sales market on the profits of the parties in the supply chain, we describe a basic scenario in which $w_{s p}=30, p=45, h=50, \beta=0.05, \psi=0.015$, $\underline{d}_{T}=50,000, \bar{d}_{T}=80,000, \underline{c}=10, \bar{c}=12, e_{r}=5, e_{s}=3, e_{g}=1, M=10,000$, $\theta=90 \%$, and $\gamma=10 \%$. Three different variations of the scenario are constructed with the following values of the advance sales market price: $w_{f p}=18, w_{f p}=21$, and $w_{f p}=24$. In each variation, the share of GPO order in the advance sales market, $\tau$, is changed from 0.65 to 1 with an incremental value of 0.007 . For the given values of market price for advance sales and share of GPO order in the advance sales market, we generate a set of problem instances by ranging the number of buyers from 1 to 50 , i.e., $n \in\{1,2,3, \ldots, 50\}$. With this configuration setting, 2500 problem instances are generated for every variation of the basic scenario.

In each set of problem configured for the given values of market price for advance sales and share of GPO order in the advance sales market, the average, maximum, and minimum of the profits that the GPO and supplier obtain are determined. Figures 5 and 6 respectively show how changes in the price of the advance sales market, $w_{f p}$, and the share of the GPO order in the advance sales market, $\tau$, affect the average profit levels of the GPO and suppliers, as well as the maximum and minimum profit levels of the GPO and suppliers. 


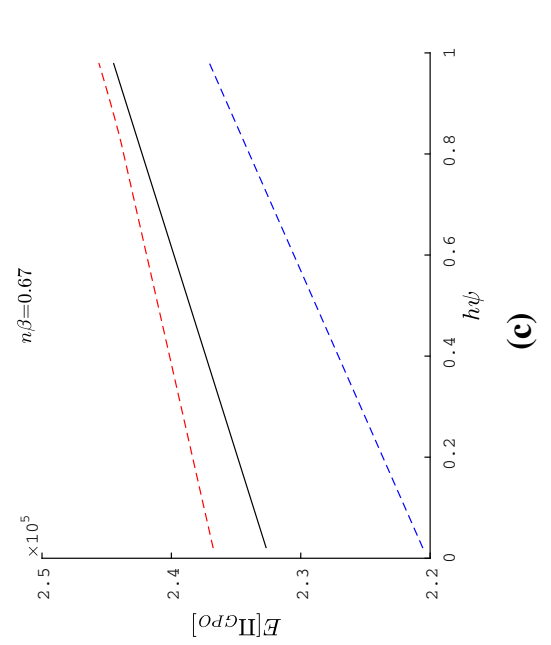

$\hat{0} \ddot{0}$

กิ

$\pi$ 远

$\stackrel{\dot{0}}{\infty}$

:อ

ले

ले

帛

$\Psi \cong$

은

$\therefore \quad \| \quad$

当 光

诖

त क 11

(

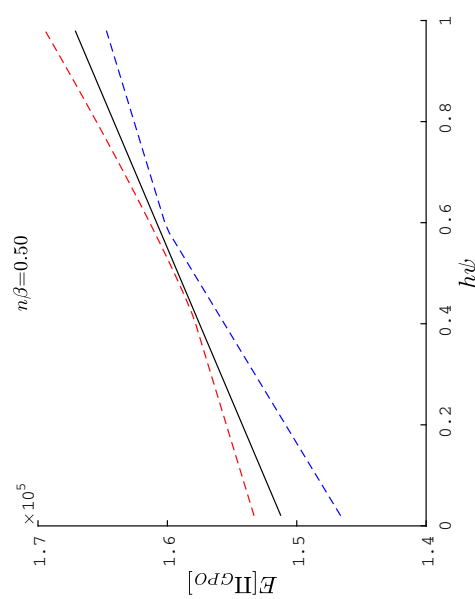

०

을

की

당

造

\%

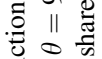

串

要음

跣

-

खे 11

- 0

o

जी 11

\& 0.

ह

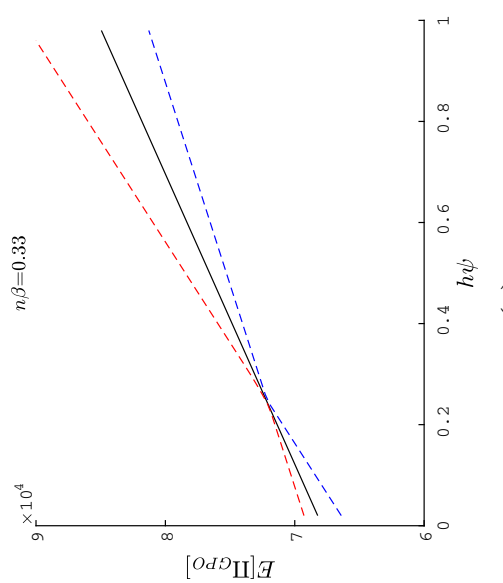

की 20

त्ञ

ए

壱保

응

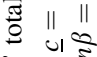

త

.

ㄴ.

क

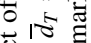

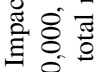

m in

节 


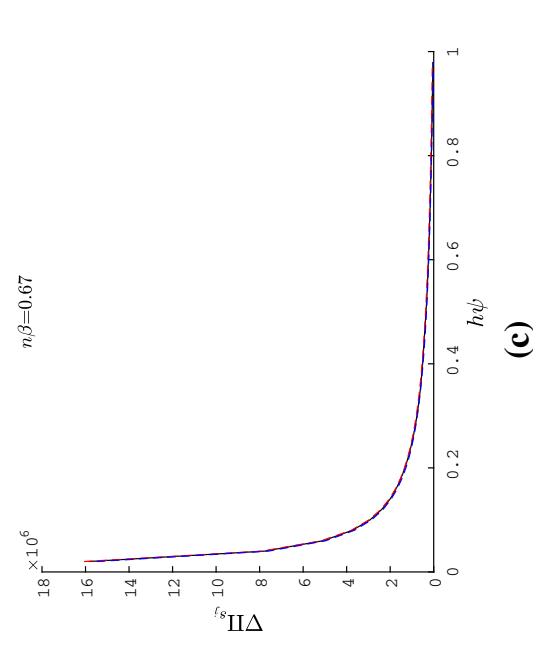

๙ุฒ

¿

is

$\therefore$ 旅

$\underbrace{0}$

$\Psi$ 产

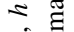

भे

(2) $\quad$ (I)

ते क⿺

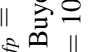

$3 \pi 5$

i

m.

D $\quad 10$

के 111

बू.

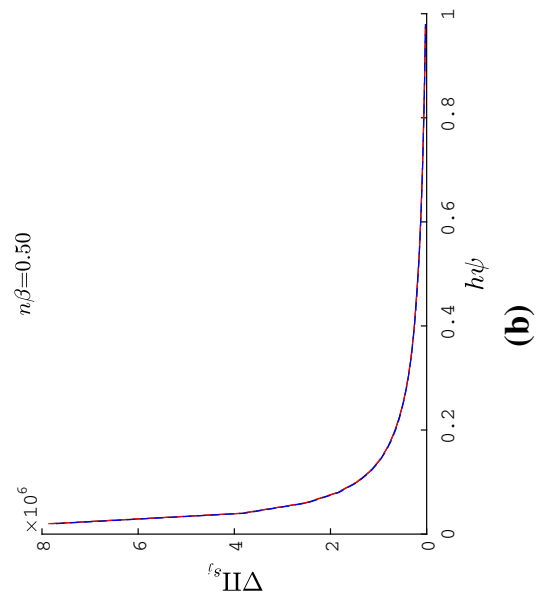

○ ᄋ क

० 11

을

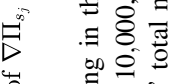

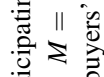

氜

| $\quad$ है

का $=m$

$\checkmark$ D

$\infty$ का

包 $\|$

के के

क व

F 11

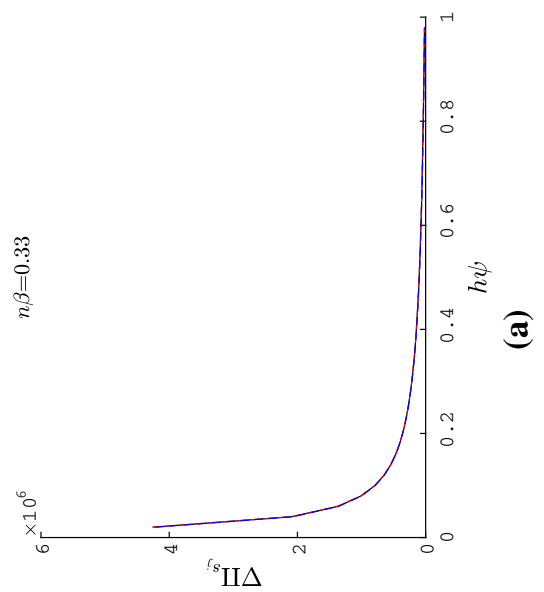

ธิ 10

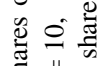

क $\|$

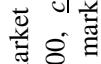

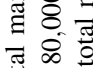

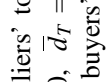

을

के

० $॥$ है

递

Eิ

$+\frac{1}{1}$

일 $\left\|_{n}\right\|$ 


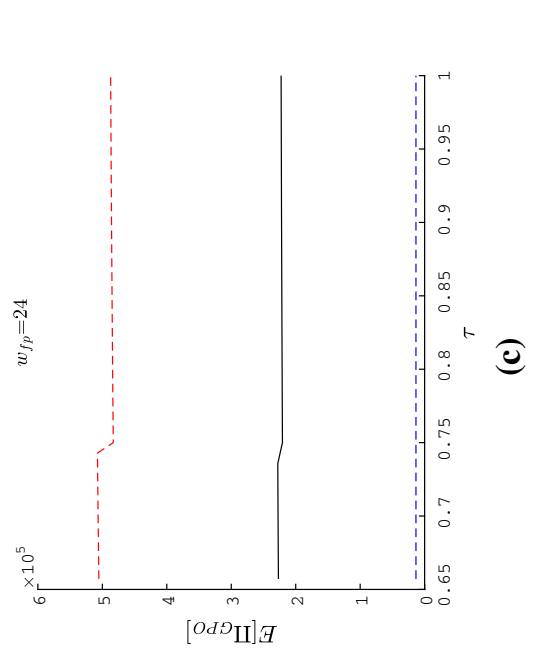

$\overbrace{0}^{2} \stackrel{0}{0}$

$\| \infty$

011

in

$\approx$ व

กิ

$\vdots$

$\hat{i} \stackrel{0}{=}$

$\approx \equiv$

4.

$=$ 这

के

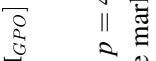

是 它豆

पे $\|$

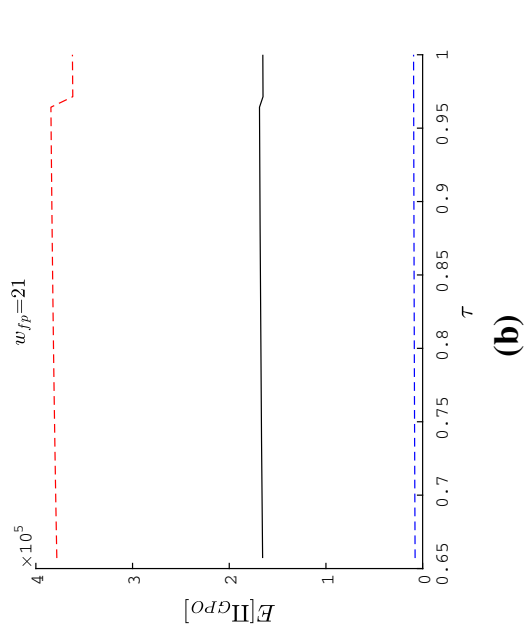

30

든

ह 11

ㅇำ

ํㅡㅇ

छ II

$=0$

응

엉ㄱ

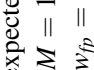

× $\geq$

o 11.0

०ै $\infty$

舫

ธิ

矛的.

跣

ป ป

¿ II

范心

$\exists \circ \cong$

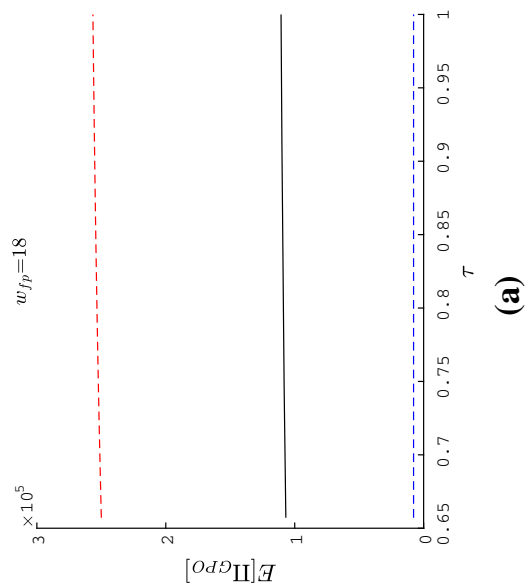

I

$\Xi U$

की

ㅎำ

인 11.

용

क⿺⿻一𠃋十

芩

䒠䠉

in 0

量 $\|$ 节 


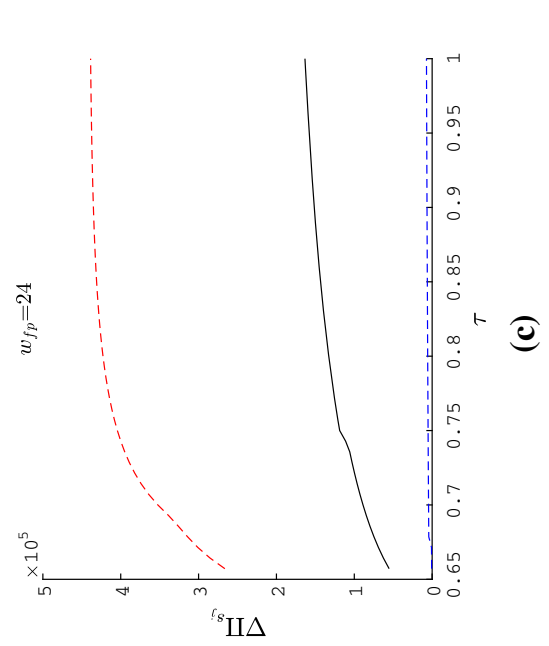

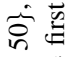

일

m.

욜

$\approx$

守

e

을

อे \%.

18

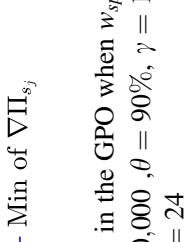

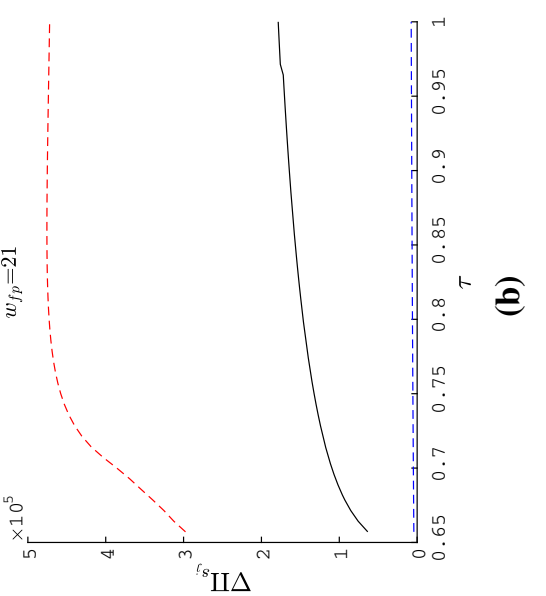

on 0

焉

원

$\exists$ 至

要更

总

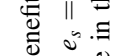

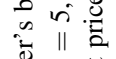

到

oำ

品

पे 50

造

券 U

घㅇํㅇ

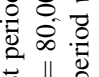

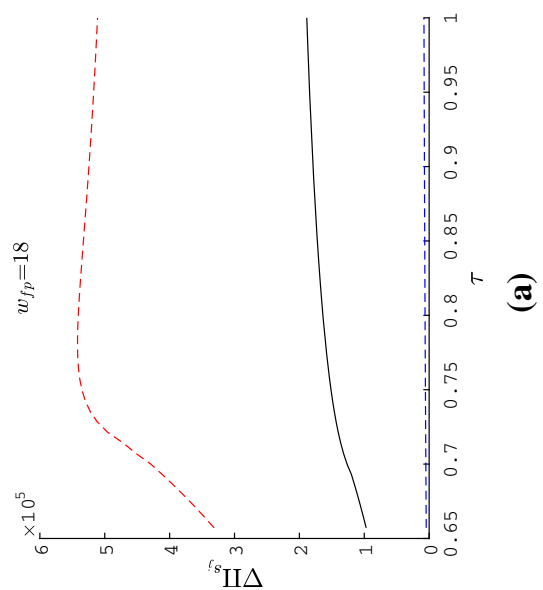

पा

语

8.

in

牙

일

능 흥

啳

के 20

이

‥ ||

छ

0 in :

की 
In Fig. 5, for a given $\tau$ value, the average profit level of the GPO rises significantly when the wholesale price increases in the first period. With an increase in $w_{f p}$, the GPO will have an opportunity to set its price at a higher level so that its marginal benefit per product is higher. Figure 5 also shows that for a given $w_{f p}$, the average profit level of the GPO usually slightly rises with an increase in the share of GPO orders in the advance sales market.

Figure 6 indicates that the GPO's positive impact on the supplier's expected profit rises with an increase in the value of $\tau$ for a given $w_{f p}$. With a high $\tau$, the GPO serves as a market maker for the suppliers, because only a small group of nonparticipating buyers can trade in the advance sales market. Accordingly, participation in GPO gives the suppliers a chance to sell their idle capacities in the first period. For the advance sales market, Fig. 6 shows that the GPO benefit in the supplier's expected profit declines with an increase in the market price. Consequently, when the market price for advance sales, that is, $w_{f p}$, is low and when GPO buyers represent a high portion of total advance orders, namely, $\tau$ is high, the marginal benefit of the GPO has an increasing effect on the suppliers' profit.

\subsection{Effects of variabilities of production cost and total demand}

Figures 7 and 8 depict the effects of variation in total demand and production costs, represented by the coefficients of variation of demand $\left(c v_{D_{T}}\right)$ and production cost $\left(c v_{C_{j}}\right)$, on the average profit levels of the GPO and supplier, respectively.

For the analysis, we define a basic scenario where $w_{s p}=30, w_{f p}=20, p=45$, $n=10, h=50, \beta=0.05, \psi=0.015, \tau=70 \%, e_{r}=5, e_{s}=3, e_{g}=1, \theta=90 \%$, and $\gamma=10 \%$. We create three different variations of the scenario considering the following values for the coefficient of variation of the total demand in the market: $c v_{D_{T}}=0.13, c v_{D_{T}}=0.31$, and $c v_{D_{T}}=0.49$. In each variation, the coefficient of variation of production cost, $c v_{c_{j}}$, is changed from 0.05 to 0.30 with an incremental value of 0.005 . For the given values of the coefficients of variation of demand and production cost, we generate a set of problem instances by ranging the supplier's total capacity from 3000 to 10,000 with an incremental step of 250 , i.e., $M \in\{3000,3250,3500, \ldots, 15000\}$. With this configuration setting, 2500 problem instances are generated for every variation of the basic scenario.

Figure 7 shows that the average profit level of the GPO increases with production cost variability. When production cost variability increases, the lower bound of the distribution of production cost and, in turn, the expected auction price decrease. As the expected auction price decreases the GPO's expected profit increases while the supplier's expected profit decreases. As a result, Fig. 8 shows that the GPO benefit in the supplier's expected profit slightly declines with an increase in the production cost variability.

For the same average demand, $\underline{d}_{T}$ decreases with an increase in $c v_{D_{T}}$. This leads to a decrease in the GPO's total revenue from advance sales. Therefore, as Fig. 7 shows, the average profit level of the GPO declines as the coefficient of variation of total demand increases. When $c v_{D_{T}}$ increases, the GPO's marginal benefit also has a 


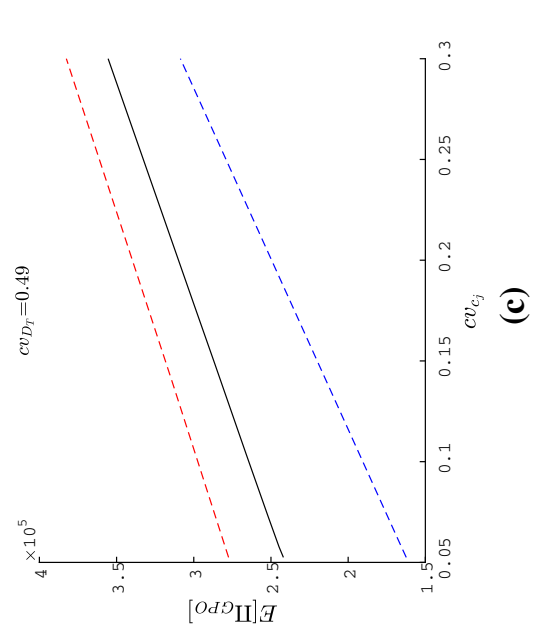

0
0
0

$\rightarrow \frac{m}{0}$

के

०ो है

c.

กิ ีี

$\leq$

등

II

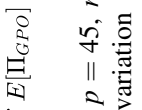

ते पै

$\|$ 责

$3 \cdot \frac{0}{0}$

คి ठृ डे

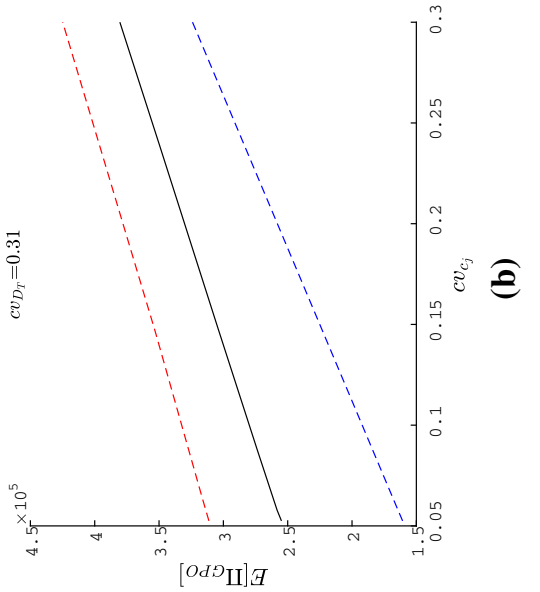

औ

ฮี ซี

3 응

후의 훙

प一

象送

흉 \&.쿵

체

웅

ชั

궁

क :

용ำ

o

ठ हैं के

जे ?े।

वृ

记

들

$\Xi \|$

×

正宁

丞

苍的壱

$\overline{\tilde{*}} \|$

क्षे

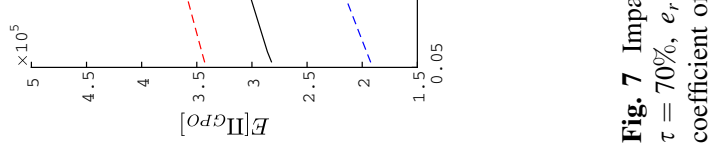




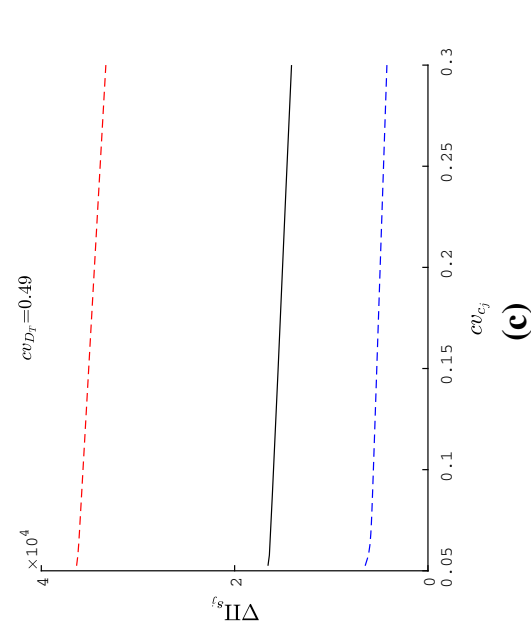

ஜீฐ

0

$\infty$

in

II

$\frac{0}{0} 8$

0

II

$\therefore$ :

ๆ

II

तें

II 호

ㄴ.

की

म $\quad$ त

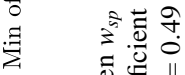

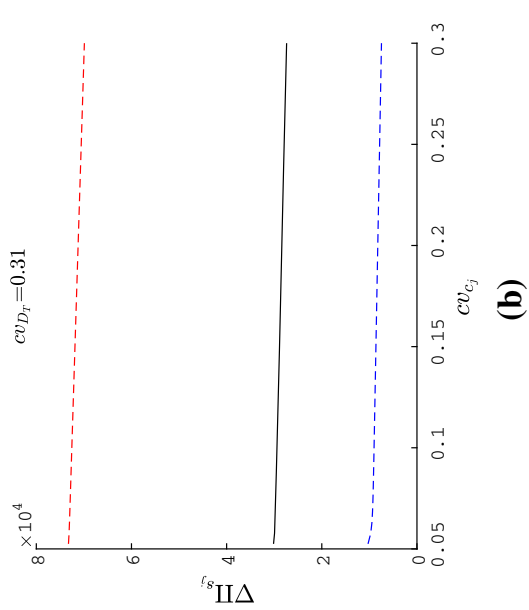

氖

380

원

का

D $\quad \Xi \triangle$

पै

药

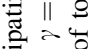

롱ㅇํㅇ

๘ㅇ

म

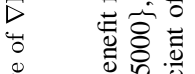

范

离

¿

을

के

छ

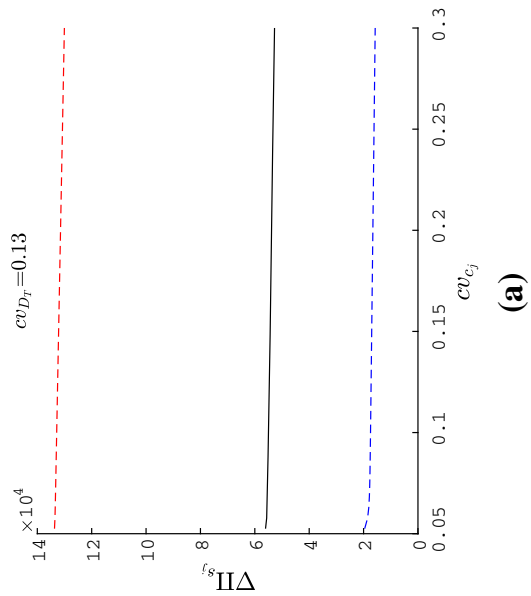

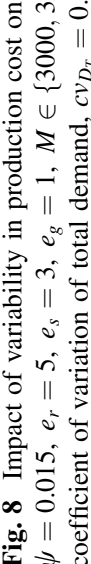


decreasing effect on the supplier's expected profit as a result of the GPO-driven market downsizing in the first period (see Fig. 8).

\subsection{Managerial insights}

Based on these numerical results, we summarize our main findings, which provide managerial insights into the operation of the group purchasing organization and its effects on suppliers and buyers, as follows:

1. Where the market share of a supplier is small, the supplier's profit significantly increases through GPO participation. This result can be attributed to the fact that participating in the GPO provides the supplier an opportunity to reach a sizable advance sales market in the first period, which cannot be done on its own. In addition, the profit of the GPO increases as the expected auction price and the excessive amount of supply from the auction decline with a decrease in the supplier's market share.

2. Participating in the GPO benefits the supplier in case the buyer's market share is high. However, the positive impact of a high buyer's market share on the expected profit of the supplier disappears when the supplier's market share goes up. Under this setting, the GPO loses its role as a market maker for the suppliers. An increase in the buyer's market share leads to more buying power and advance sales orders for the GPO. By using this advantage, the GPO sells more products to its customers, lowering the auction price in their favor. Accordingly, a higher buyer's market share implies a higher premium for the GPO.

3. High variation in production cost improves the GPO's profit but adversely affects the supplier's profit. The lower bound of the supplier's production cost declines under this setting, leading to a decrease in the expected auction price.

4. For the GPO, the total revenue obtained from advance sales decreases with an increase in the variation in total demand. For the suppliers, the increase in variation also leads to a market loss in the first period. Therefore, the GPO benefit declines for both parties as the variation in demand increases.

5. When the share of GPO orders in the advance sales market increases, the GPO provides added value to suppliers by offering them a chance to sell their idle capacities in the first period. In other words, the GPO plays a market maker role for the suppliers under this setting. On the other hand, since the expected auction price tends to decrease with an increase in the share of GPO orders in the advance sales market, the profit function of the GPO goes up.

6. As the market price for advance sales rises, the GPO can set its price at a higher level. Hence, for the GPO, the marginal profit per item procured through its channel increases. In addition, since the market price for the first period increases, the positive impact of the GPO on the supplier's expected profit decreases. 


\section{Conclusion}

We present a detailed two-period stochastic model in which there is a group purchasing organization working with a set of buyers and suppliers under demand and price uncertainty. In this model, advance sales opportunities are available in the first period to all parties in the market. The buyers and suppliers decide whether to cooperate with the GPO in the first period. If they do, the GPO employs a uniformprice reverse auction to determine the procurement price and to select the suppliers to be used for procuring advance orders of its customers. This model captures the main dynamics observed in the industrial case accurately described in Tan (2014).

Under this setting, we first characterize how buyers optimally decide whether to use the option of working with the GPO and how much to buy through advance order opportunities to maximize their profits. We then analyze the suppliers' decisions on participation in the GPO and capacity they would sell in the first period. Furthermore, the analysis for the auction mechanism is derived.

Our model captures the effects of demand uncertainty, share of GPO orders in the advance sales market, demand and price uncertainty, and variation in production cost. We investigate the effects of system parameters on the operation of the supply chain, analytically and through a range of numerical experiments. Based on these numerical results, we provide managerial insights into the operation of the group purchasing organization and its effects on suppliers and buyers. In the cases where the buyer's market share is high or the supplier's market share is low, participating in the GPO significantly benefits the supplier. Because, in these two cases, the supplier can reach a sizable advance sales market in the first period by participating in the GPO. An increase in the buyer's market share or a decrease in the supplier's market share implies a higher premium for the GPO and buyers. In addition, we observe that for the GPO and suppliers, the group buying benefit decreases as the variation in demand increases. However, high variation in production cost leads to an increase in the GPO's profit but adversely affects the supplier's profit.

We conclude that a group purchasing organization helps buyers and/or suppliers to mitigate demand and price risks in an effective way and benefits all parties subject to certain conditions. This model can be extended in several ways. First, this model can be extended to a supply chain with heterogeneous suppliers and buyers. Second, this model assumes information asymmetry between suppliers and the GPO. The GPO may generate a premium from this asymmetry. Extending this work to a setting with full information requires deriving an optimal bidding strategy for suppliers involving pricing and capacity decisions. In addition, different contract types can be applied to this structure to determine how to incentivize the buyers and suppliers to participate in GPOs effectively. Finally, the risk behavior of parties in the supply chain can be considered. These are left for future research. 


\section{Appendix A}

We first define the equations for the expected sales $S(\mathcal{A}, \mathcal{D})$, expected left-over inventory $I(\mathcal{A}, \mathcal{D})$, and expected lost sales $L(\mathcal{A}, \mathcal{D})$ for an on-hand inventory level of $\mathcal{A}$ and random demand $\mathcal{D}$ with a cumulative distribution function of $F_{D}(x)$ as

$$
\begin{gathered}
S(\mathcal{A}, \mathcal{D})=E[\min (\mathcal{A}, \mathcal{D})]=\mathcal{A}-\int_{0}^{\mathcal{A}} F_{\mathcal{D}}(x) d x \\
I(\mathcal{A}, \mathcal{D})=E\left[(\mathcal{A}-\mathcal{D})^{+}\right]=\mathcal{A}-S(\mathcal{A}, \mathcal{D}) \\
L(\mathcal{A}, \mathcal{D})=E\left[(\mathcal{D}-\mathcal{A})^{+}\right]=E[\mathcal{D}]-S(\mathcal{A}, \mathcal{D}) .
\end{gathered}
$$

Proof of Proposition 1 If the buyer does not choose to work with the GPO, its expected profit is written as in Eq. (1). The expected profit can also be expressed as $E\left[\Pi_{r}^{N G}\left(q_{N G}\right)\right]=\left(p-w_{s p}-e_{r}\right) E\left[\beta D_{T}\right]-\left(w_{f p}+e_{r}\right) q_{N G}+\left(w_{s p}+e_{r}\right) S\left(q_{N G}, \beta D_{T}\right)$.

The expected profit $E\left[\Pi_{r}^{N G}\left(q_{N G}\right)\right]$ is a concave function of $q_{N G}$, that is,

$$
\frac{\partial^{2} E\left[\Pi_{r}^{N G}\left(q_{N G}\right)\right]}{\partial q_{N G}^{2}}=-\left(e_{r}+w_{s p}\right) f_{\mathrm{B}}\left(q_{N G}\right)<0 .
$$

Under this setting, the first-order condition yields the solution of the buyer's problem:

$$
\begin{aligned}
\frac{\partial E\left[\Pi_{r}^{N G}\left(q_{N G}\right)\right]}{\partial q_{N G}} & =-\left(w_{f p}+e_{r}\right)+\left(w_{s p}+e_{r}\right) \frac{\partial S\left(q_{N G}, \beta D_{T}\right)}{\partial q_{N G}}=0 \\
& =-\left(w_{f p}+e_{r}\right)+\left(w_{s p}+e_{r}\right)\left(1-F_{\mathrm{B}}\left(q_{N G}\right)\right)=0 .
\end{aligned}
$$

Rearranging the terms in the above equation gives

$$
F_{\mathrm{B}}\left(q_{N G}\right)=1-\frac{w_{f p}+e_{r}}{w_{s p}+e_{r}} .
$$

As a result, the optimal advance order quantity for a buyer who uses the market option in the first period is defined as in Eq. (4).

When the buyer chooses to work with the GPO, its expected profit function is given as in Eq. (2). The expected profit can be rewritten as

$$
\begin{aligned}
E\left[\hat{\Pi}_{r}^{G}\left(q_{G}\right)\right]= & \theta\left(\left(p-w_{s p}-e_{r}\right) E\left[\beta D_{T}\right]-w_{r} q_{G}+\left(w_{s p}+e_{r}\right) S\left(q_{G}, \beta D_{T}\right)\right) \\
& +(1-\theta) E\left[\Pi_{r}^{N G}\left(q_{N G}\right)\right]
\end{aligned}
$$

that is also a concave function of $q_{G}$, that is, 


$$
\frac{\partial^{2} E\left[\hat{\Pi}_{r}^{G}\left(q_{G}\right)\right]}{\partial q_{G}^{2}}=-\theta\left(e_{r}+w_{s p}\right) f_{\mathrm{B}}\left(q_{G}\right)<0 .
$$

The optimal quantity that maximizes the expected profit is determined from the first-order condition as

$$
F_{\mathrm{B}}\left(q_{G}\right)=1-\frac{w_{r}}{w_{s p}+e_{r}}
$$

As a result, the optimal advance order quantity for a case where the buyer works with the GPO is given as in Eq. (3).

Proof of Proposition 2 The buyer prefers working with GPO in the first period if the expected profit for this option is greater than or equal to the profit obtained when it does not work with the GPO. The difference between the two expected profit functions, $E\left[\hat{\Pi}_{r}^{G}\left(q_{G}^{*}\right)\right]-E\left[\Pi_{r}^{N G}\left(q_{N G}^{*}\right)\right] \geq 0$, is written as

$$
\theta\left[\left(w_{s p}+e_{r}\right) S\left(q_{G}^{*}, \beta D_{T}\right)-w_{r} q_{G}^{*}-\left(w_{s p}+e_{r}\right) S\left(q_{N G}^{*}, \beta D_{T}\right)+\left(w_{f p}+e_{r}\right) q_{N G}^{*}\right] \geq 0 .
$$

Dividing both sides of the above equation with $\theta\left(w_{s p}+e_{r}\right)$ and writing $S\left(q_{G}^{*}, \beta D_{T}\right)$ and $S\left(q_{N G}^{*}, \beta D_{T}\right)$ explicitly give

$$
q_{G}^{*}\left(1-\frac{w_{r}}{w_{s p}+e_{r}}\right)-\int_{0}^{q_{G}^{*}} F_{\mathrm{B}}(y) d y-q_{N G}^{*}\left(1-\frac{w_{f p}+e_{r}}{w_{s p}+e_{r}}\right)+\int_{0}^{q_{N G}^{*}} F_{\mathrm{B}}(y) d y \geq 0 .
$$

From the proof of Proposition 1, $\left(1-\frac{w_{r}}{w_{s p}+e_{r}}\right)$ and $\left(1-\frac{w_{f p}+e_{r}}{w_{s p}+e_{r}}\right)$ can be replaced with $F_{\mathrm{B}}\left(q_{G}^{*}\right)$ and $F_{\mathrm{B}}\left(q_{N G}^{*}\right)$, respectively. Thus, the above inequality can be simplified as

$$
q_{G}^{*} F_{\mathrm{B}}\left(q_{G}^{*}\right)-q_{N G}^{*} F_{\mathrm{B}}\left(q_{N G}^{*}\right)-\int_{q_{N G}^{*}}^{q_{G}^{*}} F_{\mathrm{B}}(y) d y \geq 0 .
$$

It can be shown that the above inequality holds only if $q_{G}^{*} \geq q_{N G}^{*}$. This result gives the condition in Proposition 2.

Proof of Proposition 3 Suppliers whose production costs are greater than or equal to the estimated auction price do not work with the GPO, that is, they do not allocate any capacity to the GPO.

Suppliers whose production costs are less than $\hat{w}_{s}$ prefer using the GPO option in the first period. In this case, the expected profit function of a supplier using the GPO option is given in Eq. (6). In terms of Eq. (21), the expected profit function is restated as 


$$
\begin{aligned}
E\left[\hat{\Pi}_{s_{j}}^{G}\left(\Delta_{G}, \Delta_{N G}\right) \mid c<\hat{w}_{s}\right]= & \theta\left(\hat{w}_{s} \Delta_{G}+\left(w_{s p}-e_{s}\right) S\left(M-\Delta_{G}, D_{s}^{G}\right)\right)-c M \\
& +(1-\theta)\left(\left(w_{f p}-e_{s}\right) \Delta_{N G}+\left(w_{s p}-e_{s}\right) S\left(M-\Delta_{N G}, D_{s}^{N G}\right)\right) .
\end{aligned}
$$

This is a concave function of $\Delta_{G}$, namely,

$$
\frac{\partial^{2} E\left[\hat{\Pi}_{s_{j}}^{G}\left(\Delta_{G}, \Delta_{N G}\right) \mid c<\hat{w}_{s}\right]}{\partial \Delta_{G}^{2}}=-\theta\left(w_{s p}-e_{s}\right) f_{D_{s}^{G}}\left(M-\Delta_{G}\right)<0 .
$$

The optimal value of $\Delta_{G}$ that maximizes the expected profit subject to the constraint $0 \leq \Delta_{G}^{*} \leq \min \left\{M, Q_{G}^{*}\right\}$ is determined in accordance with the unconstrained solution for the problem, denoted as $\delta_{G}^{*}$. The unconstrained solution for the problem is obtained from the first-order condition as

$$
\delta_{G}^{*}=M-F_{D_{s}^{G}}^{-1}\left(1-\frac{\hat{w}_{s}}{w_{s p}-e_{s}}\right) .
$$

Equation (8) gives the solution of the constrained problem, using the concavity of the profit function.

If the supplier does not choose to work with the GPO, the expected profit can be written as in Eq. (7) regardless of whether or not its production cost is less than $\hat{w}_{s}$. With Eq. (21), the expected profit function is rewritten as

$$
\begin{aligned}
E\left[\Pi_{s_{j}}^{N G}\left(\Delta_{N G}^{\prime}, \Delta_{N G}\right) \mid c\right]= & \theta\left(\left(w_{f p}-e_{s}\right) \Delta_{N G}^{\prime}+\left(w_{s p}-e_{s}\right) S\left(M-\Delta_{N G}^{\prime}, D_{s}^{G}\right)\right)-c M \\
& +(1-\theta)\left(\left(w_{f p}-e_{s}\right) \Delta_{N G}+\left(w_{s p}-e_{s}\right) S\left(M-\Delta_{N G}, D_{s}^{N G}\right)\right) .
\end{aligned}
$$

$E\left[\Pi_{s_{j}}^{N G}\left(\Delta_{N G}^{\prime}, \Delta_{N G}\right) \mid c\right]$ is a concave function with respect to $\Delta_{N G}$ and $\Delta_{N G}^{\prime}$. That is,

$$
\begin{aligned}
& \frac{\partial^{2} E\left[\Pi_{s_{j}}^{N G}\left(\Delta_{N G}^{\prime}, \Delta_{N G}\right) \mid c\right]}{\partial \Delta_{N G}^{2}}=-(1-\theta)\left(w_{s p}-e_{s}\right) f_{D_{s}^{N G}}\left(M-\Delta_{N G}\right)<0, \\
& \frac{\partial^{2} E\left[\Pi_{s_{j}}^{N G}\left(\Delta_{N G}^{\prime}, \Delta_{N G}\right) \mid c\right]}{\partial \Delta_{N G}^{\prime 2}}=-\theta\left(w_{s p}-e_{s}\right) f_{D_{s}^{G}}\left(M-\Delta_{N G}^{\prime}\right)<0 .
\end{aligned}
$$

With the same steps that yield the optimal solution for the previous case, the unconstrained optimization of $E\left[\Pi_{s_{j}}^{N G}\left(\Delta_{N G}^{\prime}, \Delta_{N G}\right) \mid c\right]$, together with the concavity of the function, gives the solution of the optimal values of $\Delta_{N G}^{*}$ and $\Delta_{N G}^{\prime *}$ as given in Proposition 3.

Proof of Proposition 4 Supplier $j$, with $c \geq \hat{w}_{s}$, joins the GPO if its expected profit is higher with participation than non-participation. The difference in expected profits between these two options can be written as 


$$
\begin{aligned}
& E\left[\hat{\Pi}_{s_{j}^{G}}\left(\Delta_{N G}^{*}\right) \mid c \geq \hat{w}_{s}\right]-E\left[\Pi_{s_{j}}^{N G}\left(\Delta_{N G}^{\prime *}, \Delta_{N G}^{*}\right) \mid c\right] \\
& \quad=\left(w_{s p}-e_{s}\right)\left(M-\int_{0}^{M} F_{D_{s}^{G}}(u) d u\right) \\
& \quad-\left(w_{f p}-e_{s}\right) \Delta_{N G}^{\prime *}-\left(w_{s p}-e_{s}\right)\left(M-\Delta_{N G}^{* *}-\int_{0}^{M-\Delta_{N G}^{* *}} F_{D_{s}^{G}}(u) d u\right) .
\end{aligned}
$$

Dividing both sides of the equation by $\left(w_{s p}-e_{s}\right)$ and using $F_{D_{s}^{G}}\left(M-\delta_{N G}^{\prime}\right)$, defined in the proof of Proposition 3, simplify the above equation as

$$
\Delta_{N G}^{* *}\left(\frac{w_{s p}-w_{f p}}{w_{s p}-e_{s}}\right)-\int_{M-\Delta_{N G}^{\prime *}}^{M} F_{D_{s}^{G}}(u) d u=\Delta_{N G}^{*} F_{D_{s}^{G}}\left(M-\delta_{N G}^{\prime}\right)-\int_{M-\Delta_{N G}^{\prime *}}^{M} F_{D_{s}^{G}}(u) d u .
$$

When $\delta_{N G}^{\prime}$ is smaller than zero, the above expression yields zero considering the definition of $\Delta_{N G}^{\prime *}$. Otherwise, when $\delta_{N G}^{\prime}$ is greater than or equal to zero, it will definitely be greater than or equal to $\Delta_{N G}^{\prime *}$. With this argument and the basic properties of the cumulative distribution function, we can show that the above expression is less than or equal to zero. Therefore, given that supplier $j$ 's production cost is greater than or equal to $\hat{w}_{s}$, choosing the market option is always at least as good as or better than choosing the GPO option. Accordingly, it never allocates a portion of its capacity to the GPO.

For suppliers whose production cost is less than $\hat{w}_{s}$, the GPO will be beneficial if and only if

$$
E\left[\hat{\Pi}_{s_{j}}^{G}\left(\Delta_{N G}^{*}\right) \mid c<\hat{w}_{s}\right]-E\left[\Pi_{s_{j}}^{N G}\left(\Delta_{N G}^{* *}, \Delta_{N G}^{*}\right) \mid c\right]>0 .
$$

The above difference can be restated more explicitly as

$$
\begin{aligned}
E\left[\hat{\Pi}_{s_{j}}^{G}\left(\Delta_{N G}^{*}\right) \mid c<\hat{w}_{s}\right]-E\left[\Pi_{s_{j}}^{N G}\left(\Delta_{N G}^{* *}, \Delta_{N G}^{*}\right) \mid c\right] \\
=\hat{w}_{s} \Delta_{G}^{*}+\left(w_{s p}-e_{s}\right) S\left(M-\Delta_{G}^{*}, D_{s}^{G}\right) \\
\quad-\left(w_{f p}-e_{s}\right) \Delta_{N G}^{* *}-\left(w_{s p}-e_{s}\right) S\left(M-\Delta_{N G}^{*}, D_{s}^{G}\right) .
\end{aligned}
$$

The above function can be rewritten as

$$
\Delta_{N G}^{*}\left(1-\frac{w_{f p}-e_{s}}{w_{s p}-e_{s}}\right)-\Delta_{G}^{*}\left(1-\frac{\hat{w}_{s}}{w_{s p}-e_{s}}\right)+\int_{0}^{M-\Delta_{N G}^{*}} F_{D_{s}^{G}}(u) d u-\int_{0}^{M-\Delta_{G}^{*}} F_{D_{s}^{G}}(u) d u .
$$

If the above expression is positive, supplier $j$ prefers the GPO option given $c<\hat{w}_{s}$.

If $\hat{w}_{s} \geq w_{f p}-e_{s}$ and $w_{r} \leq w_{f p}+e_{r}$ hold, then $\Delta_{G}^{*}$ will be greater than or equal to $\Delta_{N G}^{\prime *}$ due to their definitions. Therefore, the above expression can be simplified as 


$$
\Delta_{N G}^{* *}\left(\frac{\hat{w}_{s}-w_{f p}+e_{s}}{w_{s p}-e_{s}}\right)-\left(\Delta_{G}^{*}-\Delta_{N G}^{* *}\right)\left(1-\frac{\hat{w}_{s}}{w_{s p}-e_{s}}\right)+\int_{M-\Delta_{G}^{*}}^{M-\Delta_{N G}^{*}} F_{D_{s}^{G}}(u) d u .
$$

When $\Delta_{G}^{*} \geq \Delta_{N G}^{*}$, we can show that the above equation is positive. As a result, we conclude that given $c<\hat{w}_{s}$, supplier $j$ definitely prefers working with the GPO when $\hat{w}_{s} \geq w_{f p}-e_{s}$ and $w_{r} \leq w_{f p}+e_{r}$.

Proof of Proposition 5 The capacity allocated to the GPO is exactly the same for all participating suppliers with $c<\hat{w}_{s}$. In addition, the allocated capacities are assumed to be sold in batches. Therefore, $k \Delta_{G}^{*}$ items are procured at the end of the auction. If the allocated capacities and the total amount of procured items at the end of the auction are normalized to $\Delta_{G}^{*}$, the mechanism analyzed corresponds to an auction in which bidders bid for only one of $k$ objects.

Milgrom (2004) proposes that if every bidder has a demand for just a single item and can bid for only a single unit, then the uniform-price auction would be a Vickrey auction. In this setting, truthful bidding is an optimal strategy for all bidders. Accordingly, we conclude, following (Milgrom 2004), that truthful bidding is an optimal strategy for all bidders in our setting.

Proof of Proposition 6 Raghunandanan and Patil (1972) derive the probability density and the moment generating functions of the order statistics where the sample size is random. The authors also propose a special case where the variables follow a uniform distribution over the interval $[0,1]$ and the sample size follows a binomial distribution.

In our model, the sample size follows a binomial distribution as stated in Eq. (14), and the production cost of a supplier participating in the auction is uniformly distributed between $\underline{c}$ and $\hat{w}_{s}$. Therefore, we can directly use the approach given in Raghunandanan and Patil (1972) to obtain the expression.

\section{Appendix B}

Proposition 7 For a given $w_{r}$ quoted by the GPO, the buyer will work with the $G P O$ in the first period when $E\left[\Pi_{r}^{G}\left(q_{G}^{*}\right)\right]-E\left[\Pi_{r}^{N G}\left(q_{N G}^{*}\right)\right] \geq 0$. Where $D_{T}$ follows a uniform distribution between $\underline{d}_{T}$ and $\bar{d}_{T}$, the optimal advance order quantity, $q_{G}^{*}$, is defined as

$$
q_{G}^{*}=\left\{\begin{array}{cl}
\beta \underline{d}_{T}+\beta\left(\bar{d}_{T}-\underline{d}_{T}\right)\left(1-\frac{w_{r}}{w_{s p}+e_{R}}\right) & \text { if } w_{s p}+e_{R} \geq w_{r} \geq 0 \\
0 & \text { otherwise }
\end{array} .\right.
$$

In addition, the total advance order quantity consolidated in the GPO is $Q_{G}^{*}=n q_{G}^{*}$.

On the other hand, if $E\left[\Pi_{r}^{G}\left(q_{G}^{*}\right)\right]-E\left[\Pi_{r}^{N G}\left(q_{N G}^{*}\right)\right]<0$, the buyer will use the market option in the first period. Under this setting, when $D_{T}$ is uniformly distributed between $\underline{d}_{T}$ and $\bar{d}_{T}$, the optimal advance order quantity, $q_{N G}^{*}$, is defined as 


$$
q_{N G}^{*}=\left\{\begin{array}{cl}
\beta \underline{d}_{T}+\beta\left(\bar{d}_{T}-\underline{d}_{T}\right)\left(1-\frac{w_{f p}+e_{R}}{w_{s p}+e_{R}}\right) & \text { if } w_{s p}+e_{R} \geq w_{f p}+e_{R} \geq 0 \\
0 & \text { otherwise }
\end{array} .\right.
$$

Proposition 8 Given that supplier j's production cost is lower than the estimated auction price, the supplier will be eager to work with the GPO when the GPO option is more beneficial to him compared to the market option. Where $D_{T}$ is uniformly distributed between $\underline{d}_{T}$ and $\bar{d}_{T}$, it allocates

$$
\Delta_{G}^{*}=\left\{\begin{array}{cl}
\min \left\{\delta_{G}, Q_{G}^{*}\right\} & \text { if } w_{s p}-e_{s} \geq \hat{w}_{s}>0 \\
0 & \text { otherwise }
\end{array}\right.
$$

where $\delta_{G}=M-\left(\bar{d}_{T}-Q_{T}^{G}\right) \psi\left(1-\frac{\hat{w}_{s}}{w_{s p}-e_{S}}\right)$.

Supplier $j$ never assigns a portion of its capacity for the GPO if its production cost $c$ is greater than or equal to the estimated auction price, that is, $c \geq \hat{w}_{s}$.

Where $D_{T}$ follows a uniform distribution between $\underline{d}_{T}$ and $\bar{d}_{T}$ and a GPO is operational and the supplier considers the market option more beneficial, the portion of capacity it will allocate to the buyers in the market is given as

$$
\Delta_{N G}^{* *}=\left\{\begin{array}{cl}
\min \left\{\delta_{N G}^{\prime *}, \psi \frac{n q_{N G}(1-\tau)}{\tau}\right\} & \text { if } w_{s p}-e_{s} \geq w_{s p}-w_{f p}>0 \\
0 & \text { otherwise }
\end{array}\right.
$$

where $\delta_{N G}^{\prime}=M-\left(\bar{d}_{T}-Q_{T}^{G}\right) \psi\left(\frac{w_{s p}-w_{f p}}{w_{s p}-e_{S}}\right)$.

Where $D_{T}$ is uniformly distributed between $\underline{d}_{T}$ and $\bar{d}_{T}$ and no GPO is operational, the portion allocated to the buyers in the market is defined as

$$
\Delta_{N G}^{*}=\left\{\begin{array}{cl}
\min \left\{\delta_{N G}, \psi Q_{T}^{N G}\right\} & \text { if } w_{s p}-e_{s} \geq w_{s p}-w_{f p}>0 \\
0 & \text { otherwise }
\end{array}\right.
$$

where $\delta_{N G}=M-\left(\bar{d}_{T}-Q_{T}^{N G}\right) \psi\left(\frac{w_{s p}-w_{f p}}{w_{s p}-e_{S}}\right)$.

Proposition 9 When the supplier's production cost is lower than the estimated auction price and $D_{T}$ is uniformly distributed between $\underline{d}_{T}$ and $\bar{d}_{T}$, the supplier considers the GPO beneficial to him if and only if the following inequality holds.

$$
\Delta_{G}^{*} \delta_{G}-\Delta_{N G}^{*} \delta_{N G}^{\prime}-\frac{\left(\Delta_{G}^{*}\right)^{2}-\left(\Delta_{N G}^{\prime *}\right)^{2}}{2} \geq 0
$$

On the other hand, suppliers whose production costs are greater than or equal to the estimated auction price would never consider the GPO beneficial to them. Therefore, they would never participate in the auction. 


\section{References}

Anand KS, Aron R (2003) Group buying on the web: a comparison of price-discovery mechanisms. Manage Sci 49(11):1546-1562

Aviv Y, Federgruen A (1998) The operational benefits of information sharing and vendor managed inventory (VMI) programs. Olin School of Business Working Paper

Benjaafar S, Cooper WL, Kim J (2005) On the benefits of pooling in production-inventory systems. Manage Sci 51(4):548-565

Cachon G, Marshall F (2000) Supply chain inventory management and the value of shared information. Manage Sci 46(8):1032-1048

Chen RR, Roma P (2011) Group buying of competing retailers. Prod Oper Manag 20:181-197

Erhun F (2010) Collaborative procurement. In: Cochran JJ, Cox LA, Keskinocak P, Kharoufeh JP, Smith JC (eds) Wiley encyclopedia of operations research and management science. John Wiley \& Sons, Inc. https://dx.doi.org/10.1002/9780470400531.eorms0156

Gerchak Y, Diwakar G (1991) On apportioning costs to customers in centralized continuous review inventory systems. J Oper Manag 10(4):546-551

Hao S (2000) A study of basic bidding strategy in clearing pricing auctions. IEEE Trans Power Syst 15:975-980

Hu Q, Schwarz B (2011) Controversial role of GPOs in healthcare-product supply chains. Prod Oper Manag 20(1):1-15

Hu Q, Schwarz BL, Uhan NA (2012) The impact of group purchasing organizations on healthcareproduct supply chains. Manuf Serv Oper Manag 14(1):7-23

Jin M, Yu AJ (2015) Procurement auctions and supply chain performance. Int J Prod Econ 162:192-200

Krishna V (2002) Auction theory. Academic Press, San Diego

Li X (2012) Group buying, buyer heterogeneity, and sellers' bargaining power. Decis Sci 43:761-783

Luo Z, Wang J (2015) The optimal price discount, order quantity and minimum quantity in newsvendor model with group purchase. J Ind Manag Optim 11(1):1-11

Milgrom P (2004) Putting auction theory to work. Cambridge University Press, Cambridge

Moinzadeh K (2002) A multi-echelon inventory system with information exchange. Manage Sci 48(3):414-426

Nagarajan M, Sošić G, Zhang H (2010) Stable group purchasing organizations. Marshall School of Business Working Paper No. FBE, pp 10-20

Nollet J, Beaulieu M (2003) The development of group purchasing: an empirical study in the healthcare sector. J Purch Supply Manag 9:3-10

Raghunandanan K, Patil SA (1972) On order statistics for random sample size. Stat Neerl 26(4):121-126

Saha RL, Seidmann A, Tilson V (2011) Unexpected motivations behind joining group purchasing organization. In: 44th Hawaii international conference on system sciences (HICSS 2011) pp 1-8

Tan B (2014) Zer: Power of cooperation. Koç University Graduate School of Business Case Series, vol 614-016-8. The Case Centre

Tan B, Akçay Y (2014) Assortment-based cooperation of two firms with limited capacity. IIE Trans 46:1-17

Tella E, Virolainen V (2005) Motives behind purchasing consortia. Int J Prod Econ 93:161-168

Tran T, Desiraju R (2017) Group-buying and channel coordination under asymmetric information. Eur J Oper Res 256(1):68-75

Yang YC, Cheng HK, Ding C, Li S (2017) To join or not to join group purchasing organization: a vendor's decision. Eur J Oper Res 258(2):581-589

Yu Y, Benjaafar S, Gerchak Y (2015) Capacity sharing and cost allocation among independent firms with congestion. Prod Oper Manag 24(8):1285-1310

Zhang G, Shang J, Yildirim P (2016) Optimal pricing for group buying with network effects. Omega 63:69-82

Zhang R, Liu B (2017) Group buying decisions of competing retailers with emergency procurement. Ann Oper Res 257(1):317-333

Zhao Y, Meng X, Wang S, Cheng TE (2016) Contract analysis and design for supply chains with stochastic demand. Springer, New York

Zhou E, Zhang J, Gou Q, Liang L (2015) A two period pricing model for new fashion style launching strategy. Int J Prod Econ 160:144-156 
Zhou M, Dan B, Ma S, Zhang X (2017) Supply chain coordination with information sharing: the informational advantage of GPOs. Eur J Oper Res 256(3):785-802

Zhou Y, Xie J (2014) Potentially self-defeating: group buying in a two-tier supply chain. Omega 49:42-52

Oktay Karabağ received a B.S. degree in Statistics from Ege University and an M.S. degree in Intelligent Production Systems Engineering from İzmir University of Economics. Currently, he is working toward a Ph.D. degree in the Department of Industrial Engineering and Operations Management at Koç University. His research interests include stochastic modeling, simulation, cooperation in supply chain management, and control of manufacturing systems.

Barış Tan is a Professor of Operations Management and Industrial Engineering at Koç University, Istanbul, Turkey. He received a B.S. degree in Electrical and Electronics Engineering from Boğaziçi University. He received a master's degree in Industrial and Systems Engineering, a Manufacturing Systems Engineering degree, and Ph.D. degree in Operations Research from the University of Florida. His main expertise is in design and control of production systems, analytical and numerical modeling techniques, supply chain management, and operations research. His current research interests are in stochastic modeling of operations, data-driven performance evaluation and control of manufacturing systems, and cooperation in supply chain management. 